\title{
Effect of heat treatment on the mechanical properties and microstructure of HSLA steels processed by various technologies
}

Anatoliy Zavdoveev ${ }^{1 *}$, Valeriy Poznyakov ${ }^{1}$, Thierry Baudin ${ }^{2}$, Massimo Rogante ${ }^{3}$, Hyoung Seop Kim ${ }^{4}$ Mark Heaton ${ }^{5}$, Yuriy Demchenko' ${ }^{1}$, Victor Zhukov ${ }^{1}$, Mykola Skoryk ${ }^{6}$

${ }^{1}$ Paton Electric Welding Institute of the NAS of Ukraine, 03150 Kyiv, Ukraine, avzavdoveev@gmail.com, zavdoveev@paton.kiev.ua

2 ICMMO, Univ. Paris-Sud, Université Paris-Saclay, UMR CNRS 8182, 91405 Orsay Cedex, France, thierry.baudin@universite-paris-saclay.fr

${ }^{3}$ Rogante Engineering Office, 62012 Civitanova Marche, Italy, main@roganteengineering.it

${ }^{4}$ Pohang University of Science and Technology, Department of Materials Science and Engineering, (POSTECH), Pohang 37673, Korea e-mail: hskim@postech.ac.kr

${ }^{5}$ ANT, Advanced Nano Technology, Nandor Rd, Park West business park, Dublin, mark.heaton@antsltd.com

${ }^{6}$ G. V. Kurdyumov Institute of Metal Physics of the NAS of Ukraine; NanoMedTech LLC, Kyiv, Ukraine, mykolaskor@gmail.com

* corresponding author

\section{Abstract}

This study presents a striking advance in investigating the influence of heat treatment on the microstructure and properties of high strength low-alloyed steels obtained using various technologies. In contrast to the normalization treatment, the application of the thermo-mechanical control process (TMCP) offers higher strength characteristics but less stable properties during consequent high-temperature heat treatment. It has been established that the mechanical properties of both the steels are stable up to $650{ }^{\circ} \mathrm{C}$. With an increase in the treatment temperature, the mechanical properties of the TMCP steel (grade S460M) are strongly degraded, while the normalized steel (grade S355J2) remains stable up to $950{ }^{\circ} \mathrm{C}$. This is attributed to intensive grain growth at a temperature higher than $\mathrm{A}_{c 3}$ for TMCP steel and to the microstructural stability of the normalized steel. It is shown that the structural stability during high-temperature heat treatment is controlled by a number of factors such as heating temperature and holding time, grain growth, accumulated strain, the presence of deformation texture, steel deoxidation, and dissolution/uncontrolled growth of precipitations.

Keywords: high-strength low-alloyed steels, heat treatment, mechanical properties, intensive grain growth, microstructure, electron backscatter diffraction, thermo-mechanical control process 


\section{Abbreviations}

ARPGE - software for parent austenite grains determination

$\mathrm{CE}$ - carbon equivalent

CCT - continuous cooling transformation phase diagram

EBSD - electron backscatter diffraction

EDS - energy dispersive spectroscopy

GND - geometrically necessary dislocations

HAZ - heat affected zone

HSLA - high-strength low alloyed

HV - Vickers hardness

LAM - local average misorientation

SEM - scanning electron microscopy

TMCP - thermo-mechanical control process

UTS - Ultimate tensile stress

YS - Yield stress 


\section{Introduction}

High-strength low alloyed (HSLA) steels are actively used in bridge construction, oil and gas offshore platforms, the supports of wind generators, ships, high-pressure vessels, as well as in the manufacture of railway transport [1-3]. The important task of reducing metal consumption can be solved by increasing the strength of rolled steel. There are several ways to increase the strength of low carbon steels. The first is an increase in carbon concentration, which has limitations associated with decreased ductility and deterioration in weldability. The second way is additional doping with elements that offer solid solution hardening (e.g., Mn and $\mathrm{Si}$ ). This enables an increase in the strength of metallic materials. However, to ensure ductility, the use of normalizing heat treatment is additionally required. An increase in the concentrations of $\mathrm{Mn}$ and $\mathrm{Si}$, as in the first case, also leads to a deterioration in weldability [4]. Microalloying with carbide and nitride-forming elements ( $\mathrm{Nb}, \mathrm{V}, \mathrm{Ti}$ ) [5-7] is limited by the increased cost of rolled steels. The third strengthening method is to apply heat treatment after rolling (e.g., quenching in oil, high-temperature tempering, or normalization). This, though, significantly increases the cost of manufacturing rolled steel [2]. The fourth is by obtaining a fine-grained structure of rolled steels using the method of the thermo-mechanical control process (TMCP) [3].

The most widespread technology used in manufacturing steel construction is welding [8-11]. To create reasonable welded structures operating under dynamic and variable loading conditions, more than the chemical composition and structural state had to be considered. The behavior of the various steels under thermal treatment should be taken into account also. Namely, the thermal cycle of the welding makes the most vulnerable effect on the welded metal in the zone next to the fusion line. This area is called the heat-affected zone (HAZ) and is characterized by the quenching structure. On the other hand, in the process of manufacturing welded metal structures, heating can be used to temperatures in the range from 580 to $950{ }^{\circ} \mathrm{C}$. High-temperature tempering $\left(\mathrm{T}=580-620{ }^{\circ} \mathrm{C}\right.$ ) is used to relieve welding stresses. Heating to temperatures of $680-750{ }^{\circ} \mathrm{C}$ is carried out for thermal straightening of the weldments. In some cases, for example, during hot stamping, the welded plates are heated to a temperature in the range of $900-950{ }^{\circ} \mathrm{C}$.

The mechanical properties can be lost due to the above-mentioned heat treatment of the steel (e.g., the welding thermal cycle or heat treatment associated with relatively slow heating/cooling rates). The literature states that the steel obtained using TMCP cannot be heated above $600{ }^{\circ} \mathrm{C}$ because the microstructure formed during the TMCP process after such heating cannot be restored $[9,12,13]$. However, it was not possible to uncover a detailed justification with physical reasons for this. Gorka $[14,15]$ considered the thermal 
stability of high-strength steel (700 MPa) obtained using TMCP up to temperatures of 1300 ${ }^{\circ} \mathrm{C}$. He proved that within a certain temperature range, there is a significant change in the structure and the hardening phase of the investigated steel. The question of the physical cause of these changes, however, remains unsolved.

The purpose of the present work is to study the effect of high-temperature heating on both the mechanical properties and microstructure of HSLA rolled sheet steels obtained using normalization and TMCP.

\section{Experimental}

\subsection{Materials and preparation methods}

The HSLA steels of grades S355J2 and S460M with similar chemical compositions for the main alloying elements, such as $\mathrm{C}, \mathrm{Mn}, \mathrm{Si}, \mathrm{P}$, and $\mathrm{S}$, were chosen. It was manufactured according to the standard routine at the metallurgical plant: S355J2 is received in normalized condition and S460M after TMCP. The requirements for the chemical composition of these steels are given in Table 1. As noted earlier, the maximum value of alloying elements is specified in EN10025-4, and the minimum value is not regulated. This causes a significant difference in the chemical compositions of the same steel grades. In this regard, the actual chemical compositions of the investigated steels measured using an optical emission spectrometer are given in Table 1.

Table 1. The chemical compositions (in wt\%) and CE of the investigated HSLA steels.

\begin{tabular}{|c|c|c|c|c|c|c|c|c|c|c|c|c|c|c|c|}
\hline Grade & C & $\mathrm{Si}$ & $\mathrm{Mn}$ & $\mathrm{P}$ & $\mathrm{S}$ & $\mathrm{Nb}$ & $\mathrm{V}$ & $\mathrm{Ti}$ & $\mathrm{Cr}$ & $\mathrm{Ni}$ & Mo & $\mathrm{Cu}$ & Al & $\mathrm{N}$ & $\mathrm{CE}^{\star \star \star}$ \\
\hline S460M* & 0.16 & 0.60 & 1.7 & 0.03 & 0.025 & 0.05 & 0.12 & 0.05 & 0.30 & 0.80 & 0.20 & 0.55 & 0.02 & 0.025 & 0.65 \\
\hline S460M ** & 0.15 & 0.23 & 1.30 & 0.017 & 0.013 & 0.050 & 0.01 & 0.012 & 0.09 & 0.019 & - & - & 0.025 & 0.005 & 0.38 \\
\hline S355J2* & 0.16 & 0.55 & 1.7 & 0.035 & 0.03 & 0.06 & 0.12 & 0.06 & 0.35 & 0.55 & 0.13 & 0.60 & 0.015 & 0.025 & 0.64 \\
\hline S355J2** & 0.16 & 0.24 & 1.36 & 0.016 & 0.007 & 0.031 & 0.06 & 0.016 & 0.04 & 0.030 & - & - & 0.040 & 0.007 & 0.4 \\
\hline
\end{tabular}

For the tensile test of the steel, the cylindrical samples (three samples for each measurement) with a $6 \mathrm{~mm}$ diameter for their working parts were mechanically manufactured (type II following ISO 6892:1998). The tests were carried out at an ambient temperature. For the impact strength determination, the Charpy impact tests were carried out at +20 and $-40{ }^{\circ} \mathrm{C}$ (according to the ASTM A370). The mechanical properties, namely the yield strength (YS), ultimate tensile strength (UTS), plasticity ( $\delta$, elongation for failure), and the impact strength $(\mathrm{KCV})$ at $-40{ }^{\circ} \mathrm{C}$ for the investigated steels in the initial state, are given in Table 2. 
Table 2. The mechanical properties of the investigated HSLA steels.

\begin{tabular}{|l|c|c|c|c|}
\hline $\begin{array}{c}\text { Steel/ supply } \\
\text { conditions }\end{array}$ & $\mathrm{YS}, \mathrm{MPa}$ & $\mathrm{UTS}, \mathrm{MPa}$ & $\delta, \%$ & $\mathrm{KCV}^{-40,} \mathrm{~J} / \mathrm{cm}^{2}$ \\
\hline S355J2/normalization & 370 & 530 & 32 & 200 \\
\hline S460M/TMCP* & 480 & 600 & 27 & 90 \\
\hline \multicolumn{2}{|c|}{ according to the certificate of quality for the steel } \\
\hline
\end{tabular}

Here, normalization is a condition when the steel plates are heated to $50{ }^{\circ} \mathrm{C}$ above their upper critical point $\left(\mathrm{Ac}_{3}\right)$ and are kept at it for a short time before being cooled in air. TMCP is a condition caused when steel plates are manufactured with deformation in the intercritical temperature zone ( $\left.\mathrm{Ac}_{1}-\mathrm{Ac}_{3}\right)$ followed by accelerated cooling. Such technologies as the rolling of steel sheets provide an opportunity to reach a higher level of strength with a conserved CE value (Table.1). This is a critical factor because CE is strongly connected with the formation of the cold cracks during welding (i.e., with growing CE, there is an increasing probability of cold cracks). Thus, in addition to the chemical composition, it is also essential to indicate supply conditions. Depending on the method of producing the steel, the weldability and behavior during the subsequent heat treatment will differ [16].

\subsection{Heat treatment}

As a result of the thermal cycle of welding the microstructure and properties of the initial metal are degraded. The most vulnerable point is the area of the coarse grain HAZ, whose size does not exceed 1.5-2 mm. Therefore, studies have been carried out on bulk samples to simulate the microstructure of this zone. For this purpose, a particular installation was used [17]. The samples were heated and cooled according to the thermal cycle of the welding, i.e., with the heating rate of $150^{\circ} \mathrm{C} / \mathrm{s}$ up to $1200^{\circ} \mathrm{C}$, and cooling in the temperature range of lower austenite stability $\left(600-500{ }^{\circ} \mathrm{C}\right)$ at a rate of $25^{\circ} \mathrm{C} / \mathrm{s}$.

For the thermal stability investigation of the selected HSLA steels, heat treatment was applied. The samples (initial state) were heated for 1-hour in a muffle furnace to 630, 750, and $950{ }^{\circ} \mathrm{C}$ before cooling in air. The simulated $\mathrm{HAZ}$ metal samples were heated to $950{ }^{\circ} \mathrm{C}$, kept, and cooled in the same way as previous ones.

\subsection{Structure characterization}

The preparation of the metallographic specimens for microstructural studies was carried out according to standard methods using grinding papers of different roughness (P240, P400, P600, P1200, P2000). Final polishing was carried out on a diamond 
suspension with a polishing particle size of $1 \mu \mathrm{m}$. To reveal and identify the morphology of the microstructure of the specimen, etching with a $4 \%$ solution of $\mathrm{HNO} 3$ in alcohol was conducted. The exposure time of these specimens was $4 \mathrm{~s}$, followed by washing and drying. The average grain size was evaluated by applying the linear intercept method. The chemical composition of the structural components was measured using EDS (Oxford Instruments).

The crystallographic orientation of the crystallites was determined using the EBSD technique $[18,19]$. For the formation of high-quality diffraction patterns, the surface relief should be minimal. Thus, the specimens for EBSD were prepared using standard procedures for metallographic investigation, except for the finishing stage. A silica-colloidal solution of $0.04 \mu \mathrm{m}$ was applied for polishing. MD-Nap cloth was used, the rotation frequency was $200 \mathrm{rpm}$, the pressing force of thin sections was $27 \mathrm{~N}$, and the polishing time was 3-5 minutes. An electron-scanning microscope Tescan Mira 3 LMU equipped with a Nordlys detector and HKL Channel 5 software was used for EBSD analysis of microstructural changes. At least 1500 grains of the specimen were analyzed to obtain a representative sample. The procedure was to apply a magnification of (x600-700) over a scanning area of $150 \times 100 \mu \mathrm{m}^{2}$ at a scanning step of $0.5 \mu \mathrm{m}$ (at least five measuring points per grain), binning $4 \times 4$. The degree of indication was at least $80 \%$.

The geometrically necessary dislocation (GND) density was estimated using the EBSD data. Since GNDs distort the crystal lattice, low angular misorientation changes can be measured and quantified with the help of the EBSD. For this purpose, local average misorientation (LAM) maps were constructed. These maps represent local orientation gradients. Thus, low LAM values indicate grains with relatively low GND density (depicted by blue) and high LAM values - increased GND density (represented by green and red) [2022]. In the samples processed by a thermal cycle of welding, the parent austenite grains were identified using the ARPGE program [23]. Based on orientational relations (KurdjumovSachs relationship), this program allowed restoring the parent austenite from the bainite structure.

\section{Results}

\subsection{Effect of heat treatment on the mechanical properties}

The experimental results have shown that the strength and plastic characteristics (Figures 1 and 2) of the investigated steel samples remained almost unchanged after heating up to $650{ }^{\circ} \mathrm{C}$. 


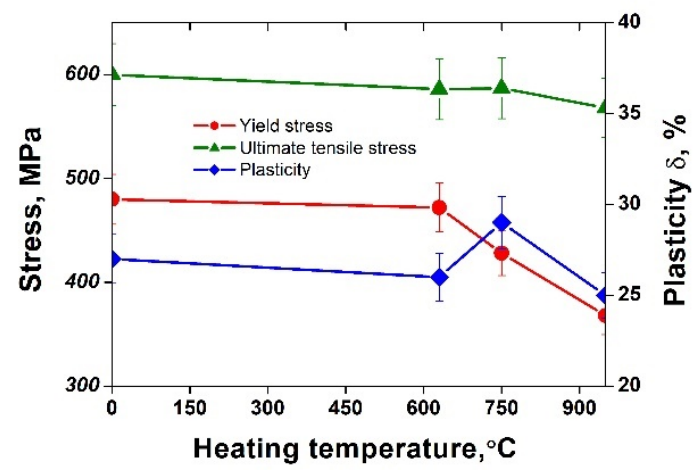

a)

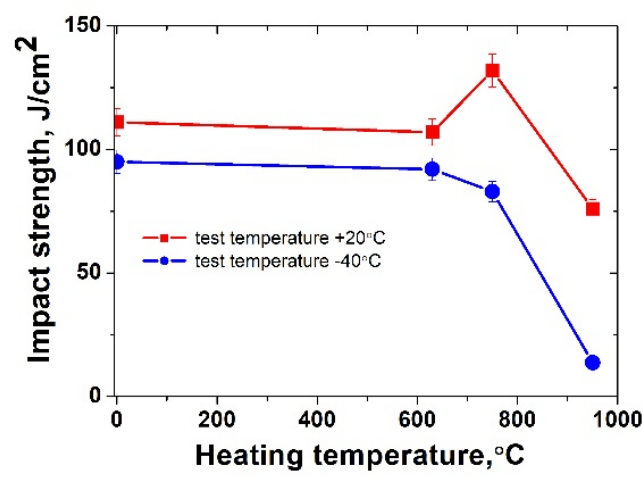

b)

Fig. 1. Influence of heating on the mechanical properties of the as-rolled steel grade S460M: Yield stress, Ultimate tensile stress, Plasticity - a; Impact strength - b.

Noticeable changes in the mechanical properties and impact strength of the S460M steel are observed only when heated to $750{ }^{\circ} \mathrm{C}$. A yield strength decrease of $10 \%$ is observed, and the plasticity remains almost unchanged, while the impact strength rises somewhat. An increase in the heating to $950{ }^{\circ} \mathrm{C}$ leads to a more substantial reduction in the yield strength of the S460M steel, by almost 25\%. Its impact strength, at the same time, decreases by $30 \%$ at the samples tested at $20^{\circ} \mathrm{C}$, and by $4-6$ times at $-40{ }^{\circ} \mathrm{C}$ (Figure 1).

Unlike the steel grade S460M, the steel grade S355J2 is more thermally stable. Regardless of the heating temperature, it keeps the values of the mechanical properties (YS, UTS, $\delta$ ) within the limits of $6 \%$ error, compared with the initial state (Figure 2). The impact strength, as in the case of the S460M steel sample, after heating to $750{ }^{\circ} \mathrm{C}$, regardless of the test temperature, the impact strength slightly increased. With a further increase in heating temperature (up to $950^{\circ} \mathrm{C}$ ), the impact strength values practically return to the initial state for the S355J2 steel.

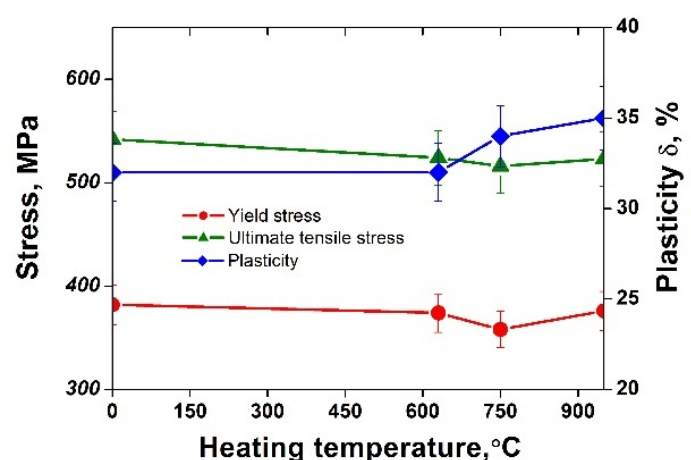

a)

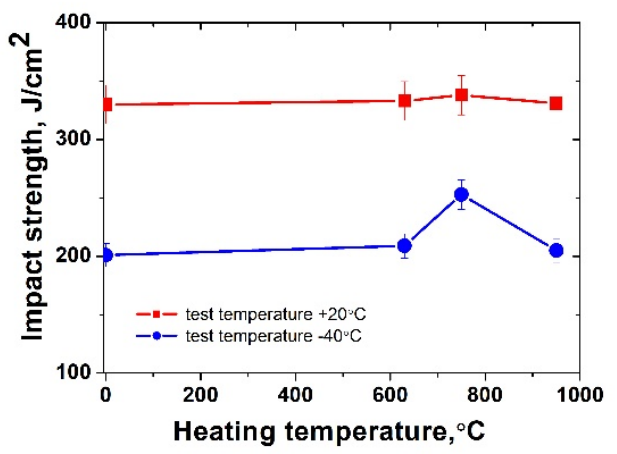

b)

Fig. 2. Influence of the heating on the mechanical properties of the as-rolled steel grade S355J2: Yield stress, Ultimate tensile stress, Plasticity - a; Impact strength - b. 
The mechanical properties of the simulated HAZ metal (rapid heating/cooling regime) are presented in Figure 3. It is clearly seen that such heat treatments lead to significant increase of the YS and UTS while impact strength drops drastically. Such behavior of the mechanical characteristics is widespread for the quenching processes.

Due to the fact that the most remarkable changes in the mechanical properties of S460M steel occurred after it was heated to $950{ }^{\circ} \mathrm{C}$, this heat treatment temperature was used in further studies, which were carried out for the HAZ. It has been established that the strength characteristics of the HAZ metal drop after heating to $950{ }^{\circ} \mathrm{C}$ for both of the investigated steels, and that the plasticity increases significantly (Figure 3). The ultimate tensile strength of the HAZ metal of the S355J2 steel after exposure of the samples for 1 hour at $950{ }^{\circ} \mathrm{C}$ (Figure 3f) remains higher than in the initial state. It is important to note that the strength and plasticity characteristics of the HAZ metal for both of the investigated steels after exposure to $950{ }^{\circ} \mathrm{C}$ are similar. High-temperature heating (950 ${ }^{\circ} \mathrm{C}$ ) of the HAZ metal leads to an increase in the impact strength of the S355J2 steel, and a slight decrease in S460M steel (Figure 3d,h).
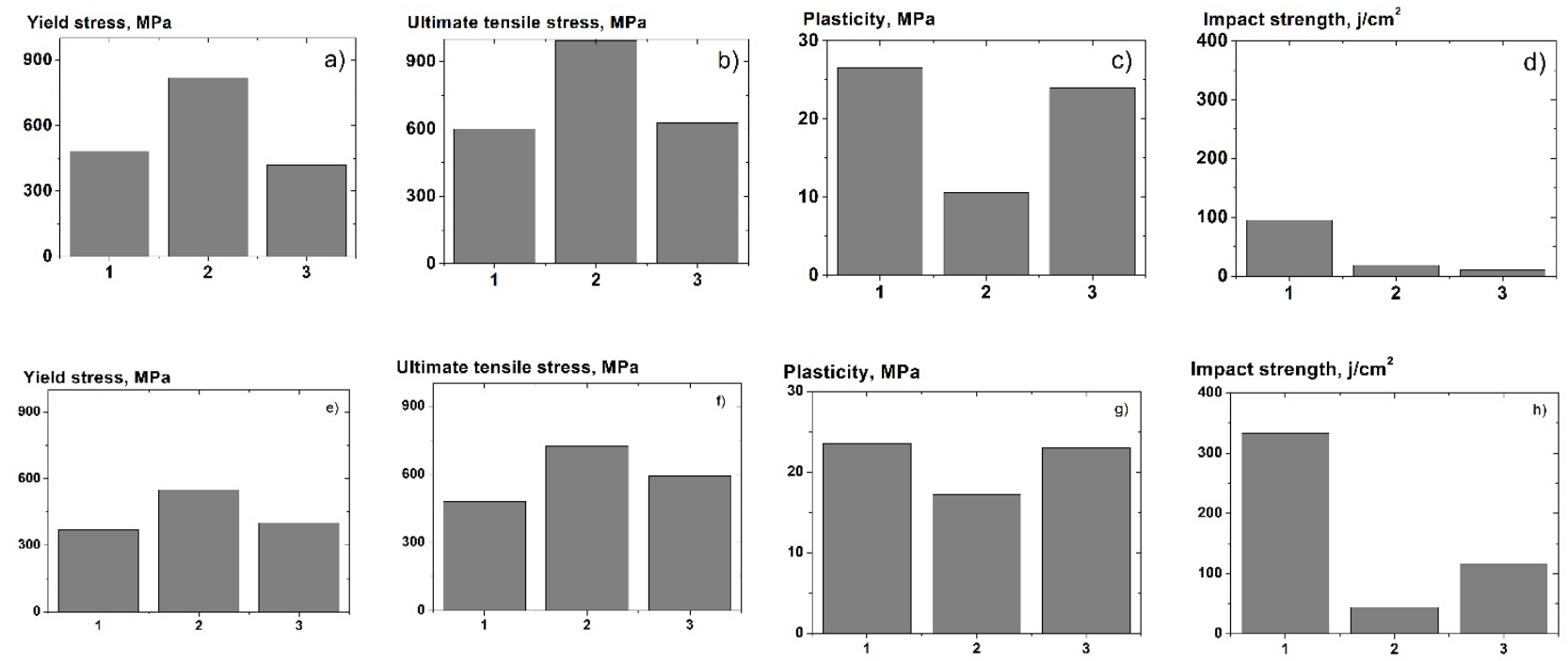

Fig. 3. The mechanical properties of the investigated steels after thermal treatment. Yield stress - a,e; Ultimate tensile stress - b,f; Plasticity - c,g; Impact strength - d,f. Steel grade S460M - a,b,c,d. Steel grade S355J2 - e,f,g,h. As-rolled (initial state) -1; HAZ - 2; HAZ with heating to $950^{\circ} \mathrm{C}-3$.

\subsection{Effect of heat treatment on the structure}

The microstructure of the considered steels in the initial state is ferritic-pearlitic with average grain sizes of $\sim 20 \mu \mathrm{m}$ for S355J2 steel and $10 \mu \mathrm{m}$ for S460M steel (see Figure 4). 
In the case of steel production through the normalization procedure (S355J2 steel), the microstructure is characterized by a chaotic distribution of orientations. The steel produced through TMCP (S460M steel) has a significantly pronounced texture with a predominance of directions $<101>$ (// normal direction to the rolling plane) as indicated by the EBSD orientation distribution maps and poles figures (Figure 5). For BCC lattice metals \{101\} crystallographic planes are most favorable for the dislocation slip. The pole figures (Figure $5 \mathrm{c}, \mathrm{d})$ for this structure confirm the presence of $\{110\}<111>$ texture for steel grade S460M, and separate pole peaks for steel grade S355J2. The difference in grain size is also observed in S460M steel, whereas for S355J2 steel, the grain size distribution is more uniform.

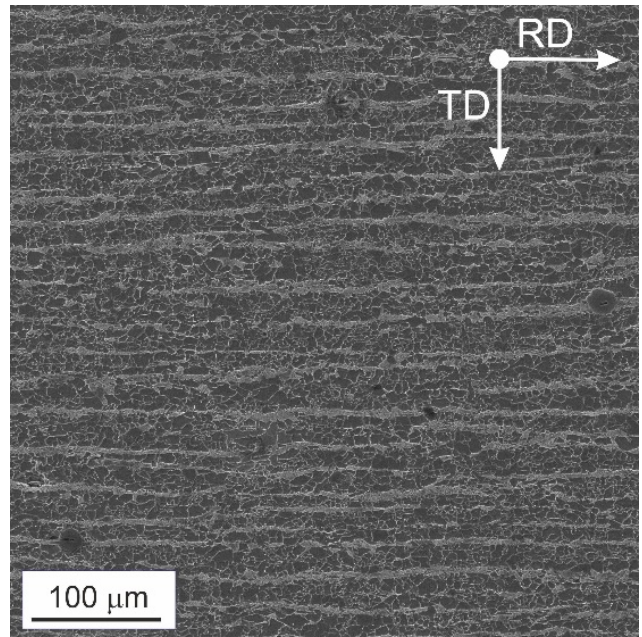

a)

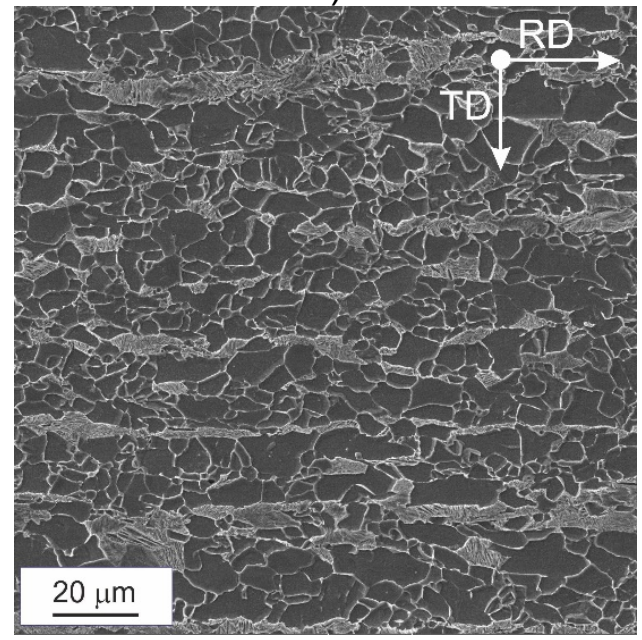

c)

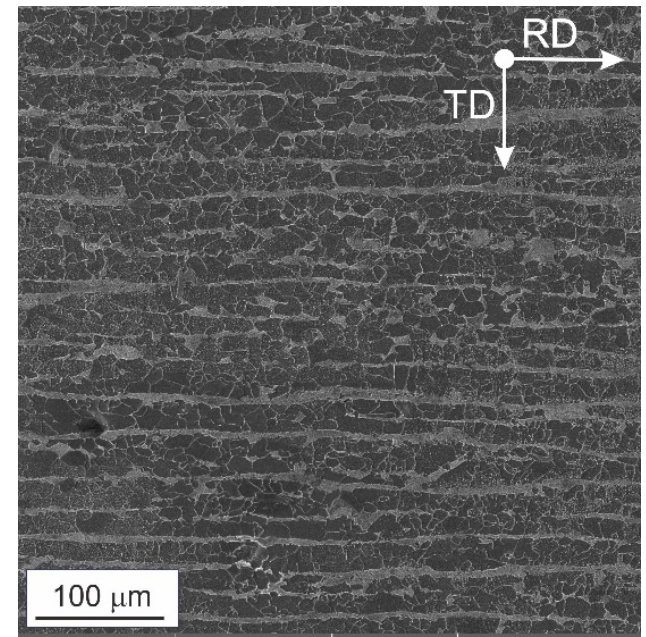

b)

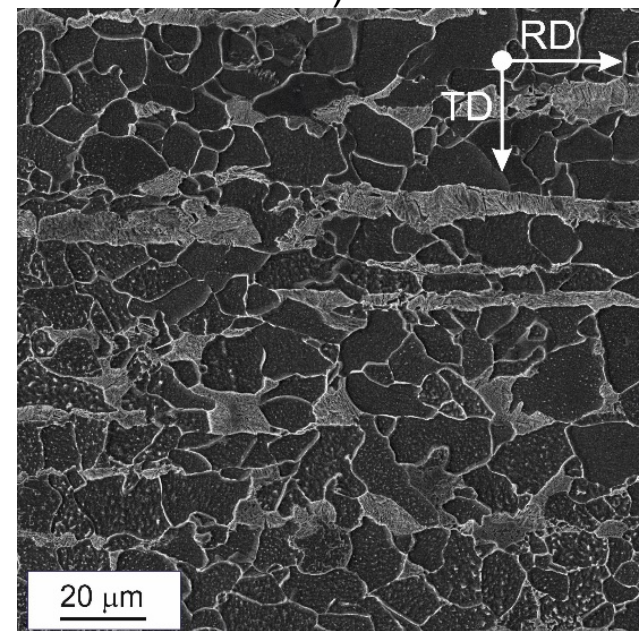

d)

Fig. 4. The SEM microstructures of the investigated steels in as-rolled condition (initial state). a,c - steel grade S460M; b,d - steel grade S355J2. The rolling direction is horizontal.

The studied steels in the initial state heated to $950{ }^{\circ} \mathrm{C}$ exhibit completely different behavior. In S355J2 steel, there is a moderate grain growth from the initial state of $20 \mu \mathrm{m}$ to 
25-30 $\mu \mathrm{m}$ (1.5 times growth) and the dispersed distribution of pearlite. In comparison, S460M steel is characterized by significant grain growth (Figures 6a and 7a) from $10 \mu \mathrm{m}$ in the initial state to up to $35 \mu \mathrm{m}$ after the heating up to $950^{\circ} \mathrm{C}$ (i.e., 3.5 times) and a smaller fraction of pearlite component. Thus, during heating up to $950^{\circ} \mathrm{C}$ the transformation of the ferritic pearlitic into austenitic structure occurs with the following growth of the austenite grains size. As a sequence of further cooling, the austenitic structure is transformed back to the ferritic pearlitic and the size of last is determined by the grain boundaries of the previous austenite grains. The reasons for such grains growth evolution are considered below.

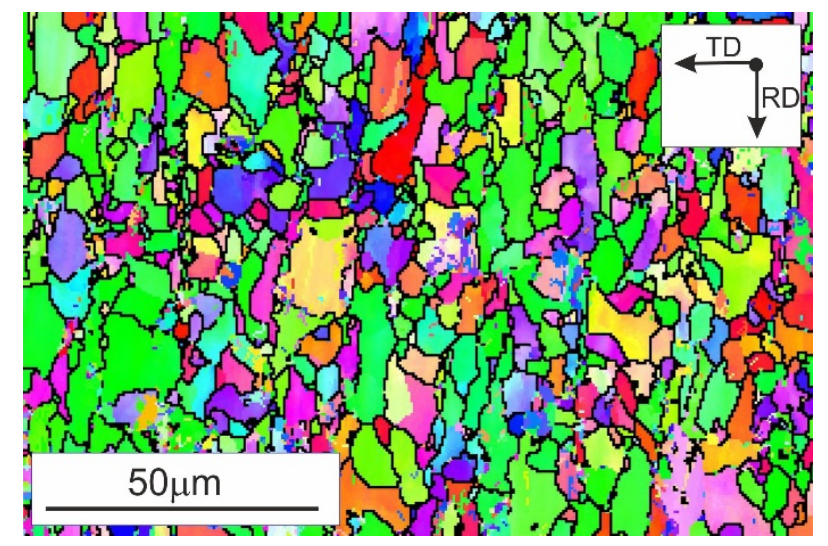

a)

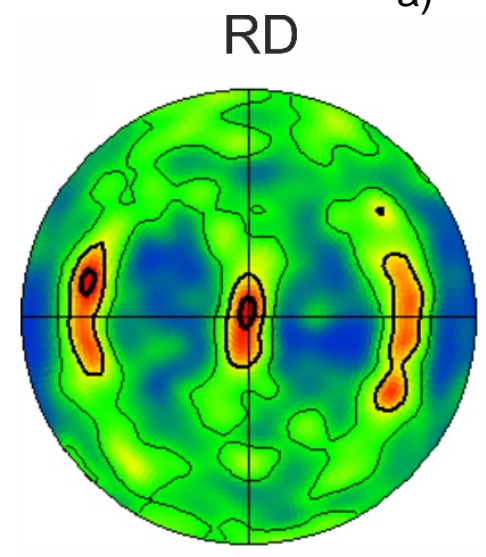

\{101\}

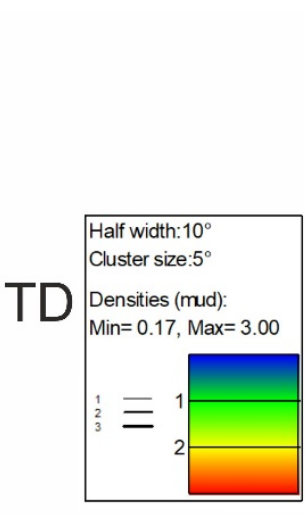

c)

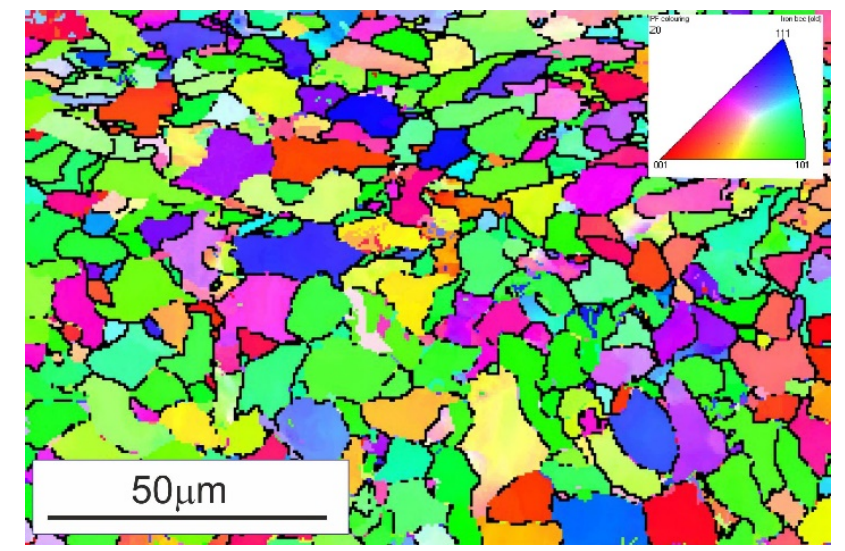

b)

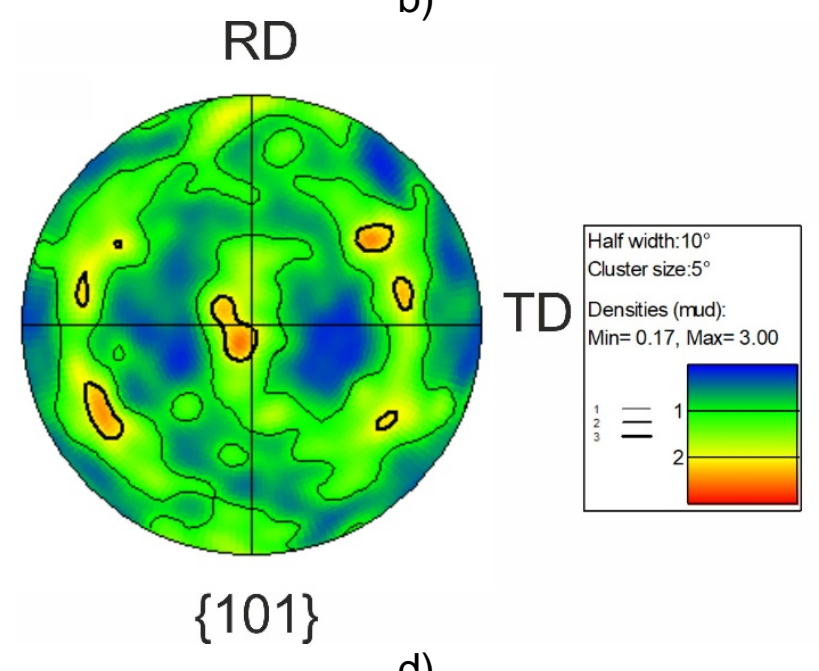

Fig. 5. The EBSD orientation maps $(a, b)$ and pole figures $(c, d)$ of the investigated steels in as-rolled condition (initial state). a,c - steel grade S460M; b,d - steel grade S355J2; IPF, crystallographic direction // ND (Normal direction)

Microstructural analysis data has shown that the HAZ of the investigated steels has similar morphology and consists of a mixture of bainite and ferrite (Figure $6 \mathrm{c}$ and $\mathrm{d}$, Figure $7 \mathrm{c}$ and d). The hardness values for such microstructures are $280 \pm 14 \mathrm{HV}$ and $260 \pm 13 \mathrm{HV}$ for S460M and S355J2 steels, respectively. 


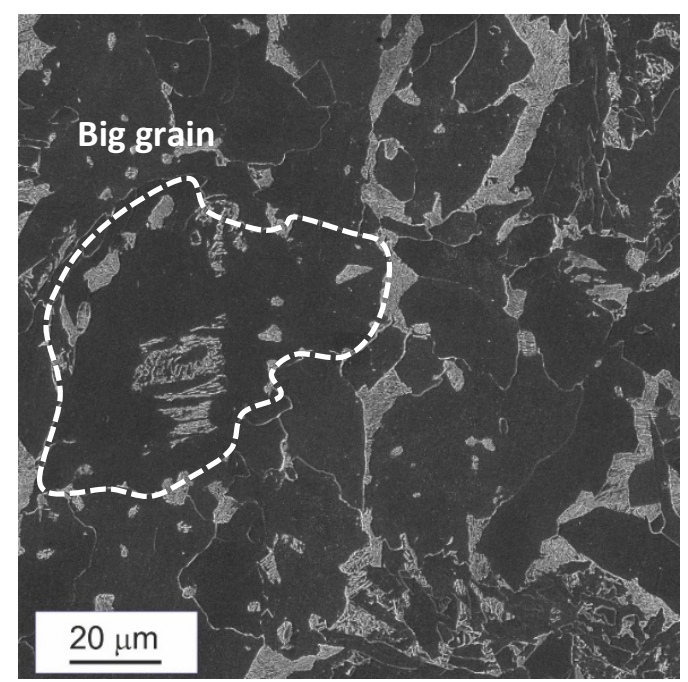

a)

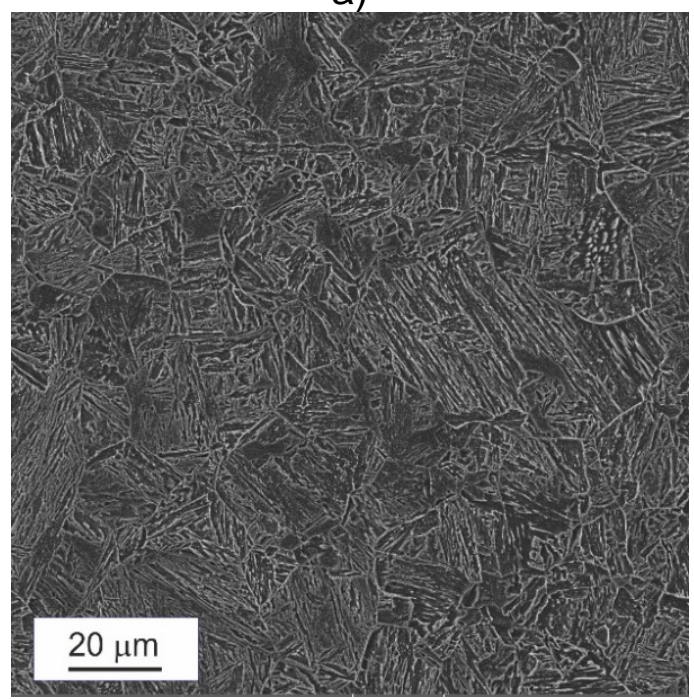

c)

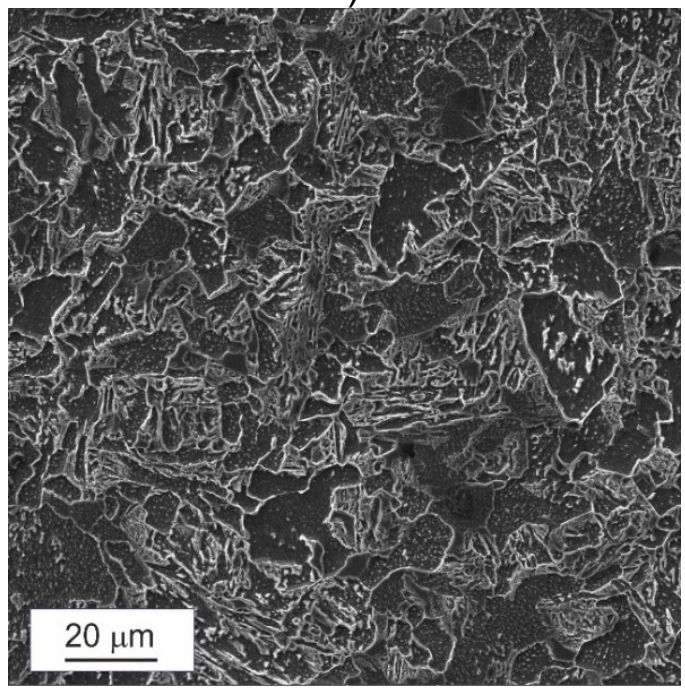

e)

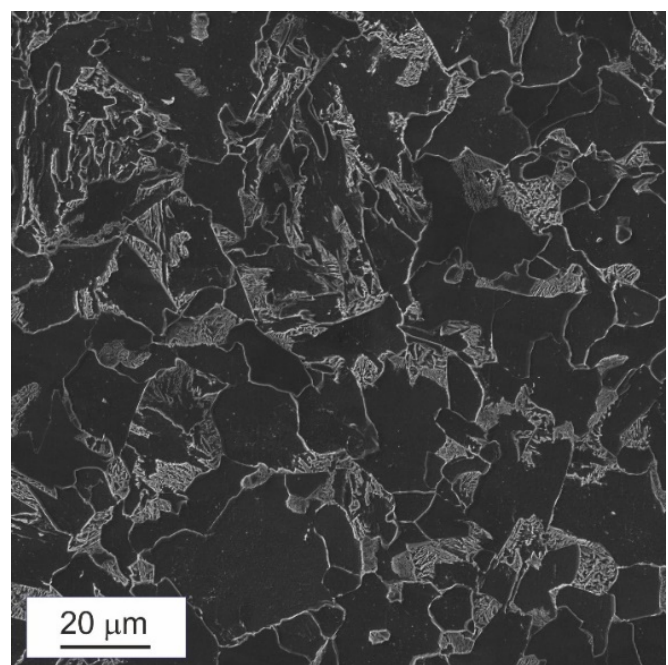

b)

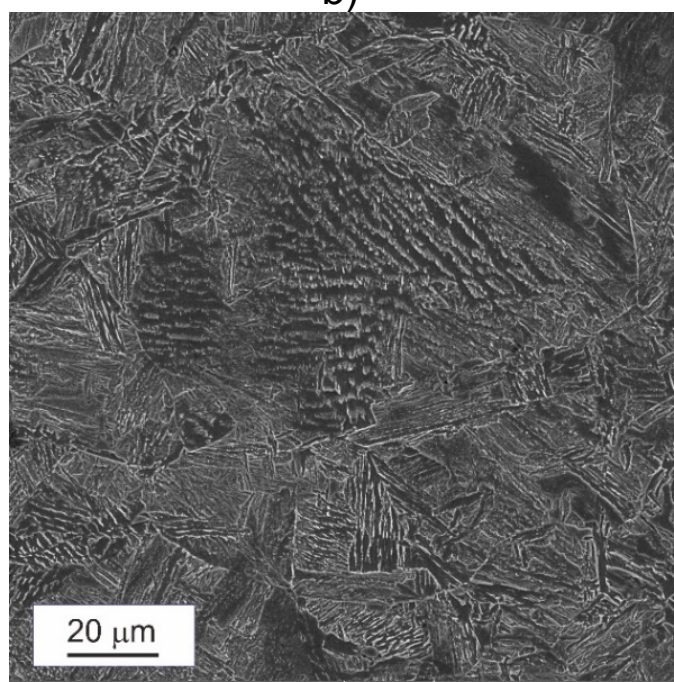

d)

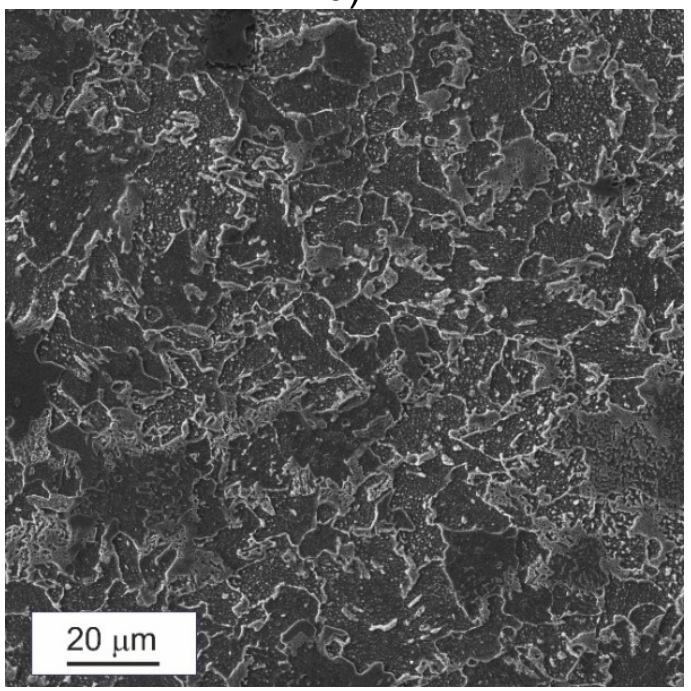

f)

Fig. 6. The SEM microstructure of the as-rolled steels after high-temperature heating to $950{ }^{\circ} \mathrm{C}(\mathrm{a}, \mathrm{b}), \mathrm{HAZ}$ metal $(\mathrm{c}, \mathrm{d}), \mathrm{HAZ}$ metal after high-temperature heating to $950{ }^{\circ} \mathrm{C}(\mathrm{e}, \mathrm{f})$; $(a, c, e)$ - steel grade S460M, (b,d,f) - steel grade S355J2 


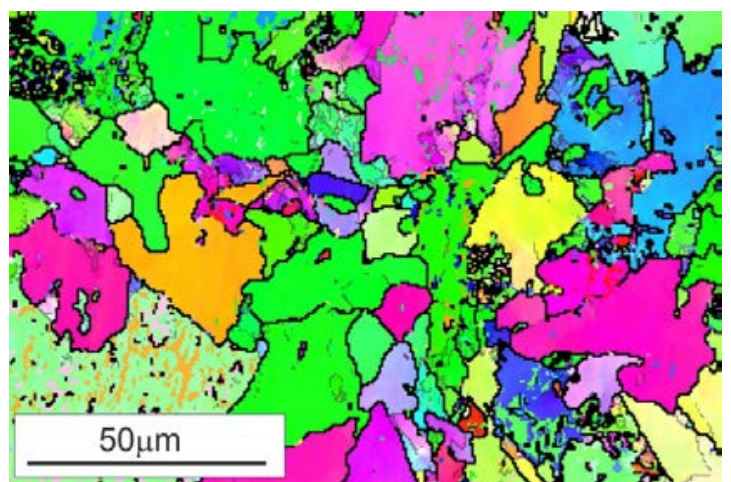

a)

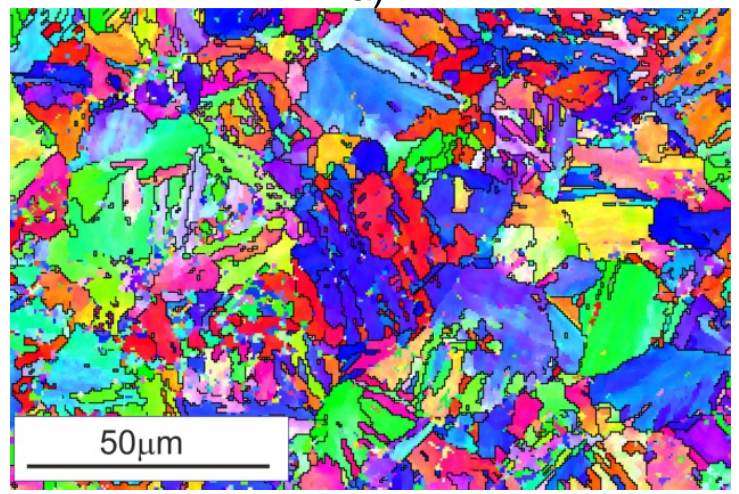

c)

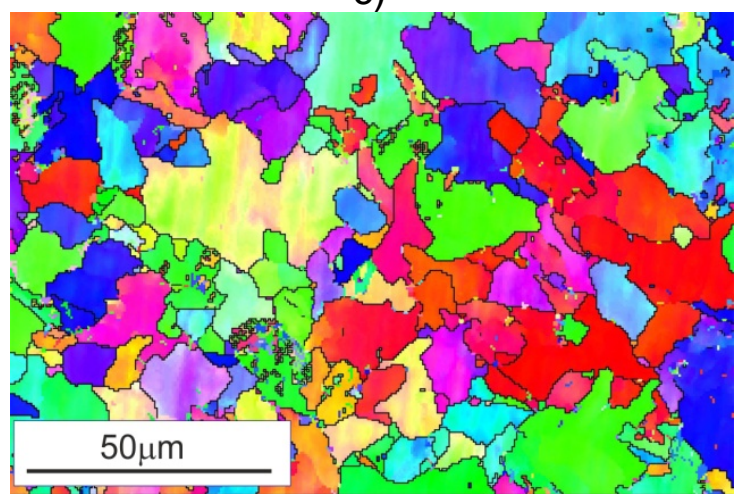

e)

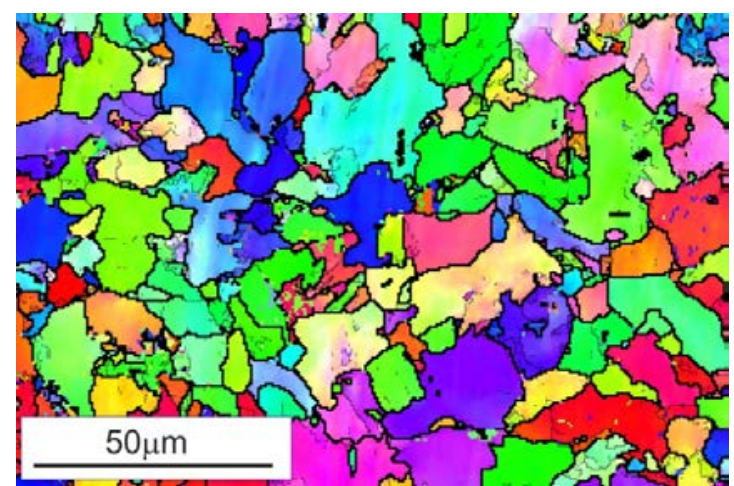

b)

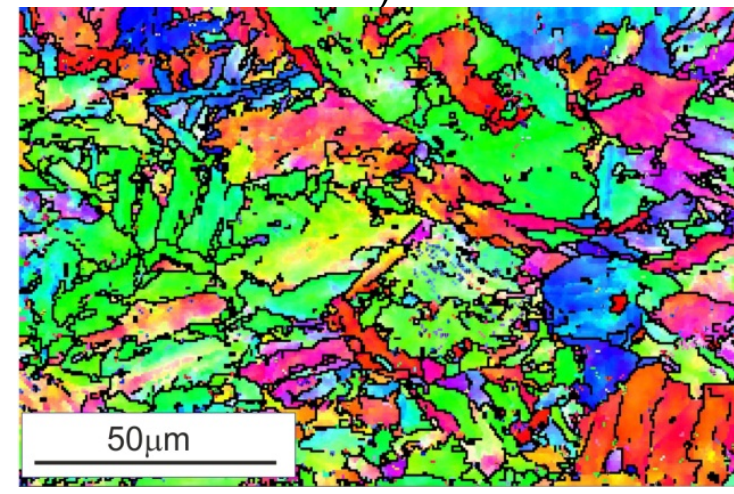

d)

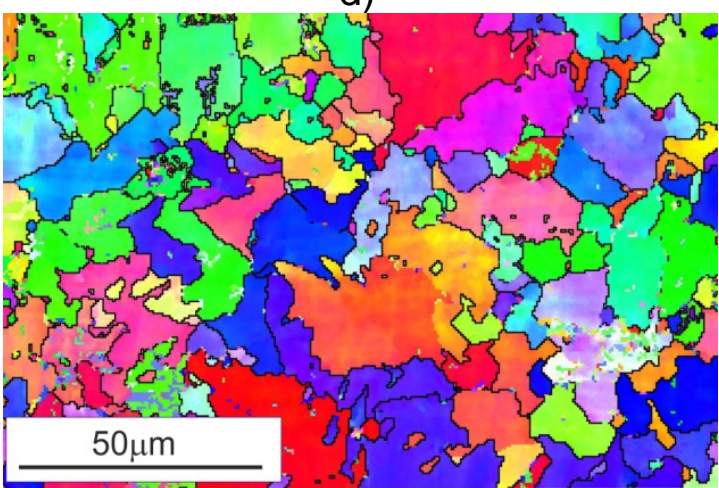

f)

Fig. 7. The EBSD orientation maps of the as-rolled steels after high-temperature heating to $950{ }^{\circ} \mathrm{C}(\mathrm{a}, \mathrm{b}), \mathrm{HAZ}$ metal $(\mathrm{c}, \mathrm{d}), \mathrm{HAZ}$ metal after high-temperature heating to $950{ }^{\circ} \mathrm{C}$ $(e, f) ;(a, c, e)$ - steel grade S460M, (b,d,f) - steel grade S355J2

The grain orientation analysis (Figure $7 \mathrm{c}$ and $\mathrm{d}$ ) shows no pronounced deformation texture for S460M steel. Under the heat treatment $\left(950{ }^{\circ} \mathrm{C}\right)$, the simulated HAZ metal structure approaches a more equilibrium ferritic-pearlitic form. The average grain size for the investigated steel, in this case, is very close and equal to 25-30 $\mu \mathrm{m}$ (Figures 6 e,f and 7 e,f).

\section{Discussion}

The obtained results indicate that for the investigated steels in the initial state, the maximum changes in the mechanical properties and microstructure take place during hightemperature heating to $950{ }^{\circ} \mathrm{C}$. In contrast, the HAZ metal is less susceptible to such influence. 
To explain this effect, the factors affecting the mechanical properties of the steel were analyzed. One of the main mechanical properties is Yield strength $\left(\sigma_{y}\right)$, which can be represented by a sum of terms [24-26]:

$$
\sigma_{y}=\sigma_{0}+\sigma_{\rho}+\sigma_{\mathrm{ss}}+\sigma_{\mathrm{ppt}}+\sigma_{\mathrm{gs}},
$$

where $\sigma_{0}$ is the friction stress of the crystal lattice, $\sigma_{\rho}$ is the hardening stress due to dislocation interactions, $\sigma_{s s}$ is the solid solution hardening stress, $\sigma_{p p t}$ is the stress due to hardening by the precipitating particles, and $\sigma_{g s}$ is the stress due to hardening by grains refinement, which increases the volume fraction of the grain boundaries. The Hall-Petch equation (2) is

$$
\sigma_{\mathrm{gs}}=\sim \frac{\mathrm{k}_{\mathrm{y}}}{\sqrt{\mathrm{d}}},
$$

where $k_{y}$ is the strengthening coefficient $=0.74$ for low-carbon ferritic steel [27] and $d$ is the average grain size. These components describe the relationship between the yield strength and grain size, indicating that a significant contribution of the $\sigma_{g s}$ term to the overall strengthening in low-carbon low-alloyed steels can reach $40 \%$. The contributions of each of the $\left(\sigma_{0}=2 \cdot G \cdot 10^{-4} \leq 5-10 \%, \quad \sigma_{\rho}=\alpha \cdot m \cdot G \cdot b \cdot \rho^{1 / 2} \leq 3-5 \%, \quad \sigma_{\mathrm{ss}}=\sum_{i=1}^{n} K_{i} C_{i} \leq 25 \%\right)$ components to the total strengthening of the low-carbon low-alloyed steel do not exceed the value of $\sigma_{g s}[27]$.

In the production of steel by applying the normalizing heat treatment, an important strengthening mechanism (further to a solid solution ( $\left.\sigma_{s s}\right)$ ) is the presence of dispersed particles, such as carbides, nitrides, and intermetallic compounds ( $\sigma$ ppt). The steel is conditioned such that during the normalizing heat treatment, only slight grain growth occurs and strain-hardening is annihilated. Meanwhile, in the steels obtained by the TMCP method, strengthening due to the formation of a finely dispersed structure $\left(\sigma_{g s}\right)$ and strain-hardening plays a key role.

With high-temperature heating, grain growth occurs that entails changes in the mechanical properties. The intensity of the grain growth process is determined by several factors, such as:

- $\quad$ heating temperature and holding time [28];

- accumulated strain [29];

- the presence of deformation texture (rolling) [30];

- $\quad$ steel deoxidation [30];

- carbonitrides [30];

- dissolution/uncontrolled growth of precipitations (Zener pinning effect) [31]. 
Thus, in further consideration, the primary attention is paid to the grain growth phenomenon during heating up to temperatures above $A_{c 3}$.

\subsection{Heating temperature and holding time}

According to the phase diagram Fe-C, steels are characterized by the critical points $A_{c 1}$ and $A_{c 3}$. The transformation kinetics for any particular steels depends on the selected heating temperature and the range where this temperature will be chosen. The austenite grain growth is controlled by diffusion at the heat treatment temperature. The Ac1and Ac3 points are considered, to show the kinetic of the heat treatment process. For high temperature $950^{\circ} \mathrm{C}$ heat treatment, when the temperature gets $A_{c 1}$ the transition from ferritic-pearlitic into austenitic phase is started, and when the temperature gets Acз fully austenitic structure is formed and only then austenitic grain start growing. But all is determined by the time of being above critical points $A_{c 1}$ and $A_{c 3}$. For the investigated steels, the critical points have the following different values (Figure 8): $A_{c 1}=714^{\circ} \mathrm{C}, A_{c 3}=883^{\circ} \mathrm{C}$ for S460M; $A_{c 1}=750^{\circ} \mathrm{C}$ and $A_{c 3}=930^{\circ} \mathrm{C}$ for S355J2 (data obtained using Gleeble 3800 dilatometric unit [32]).

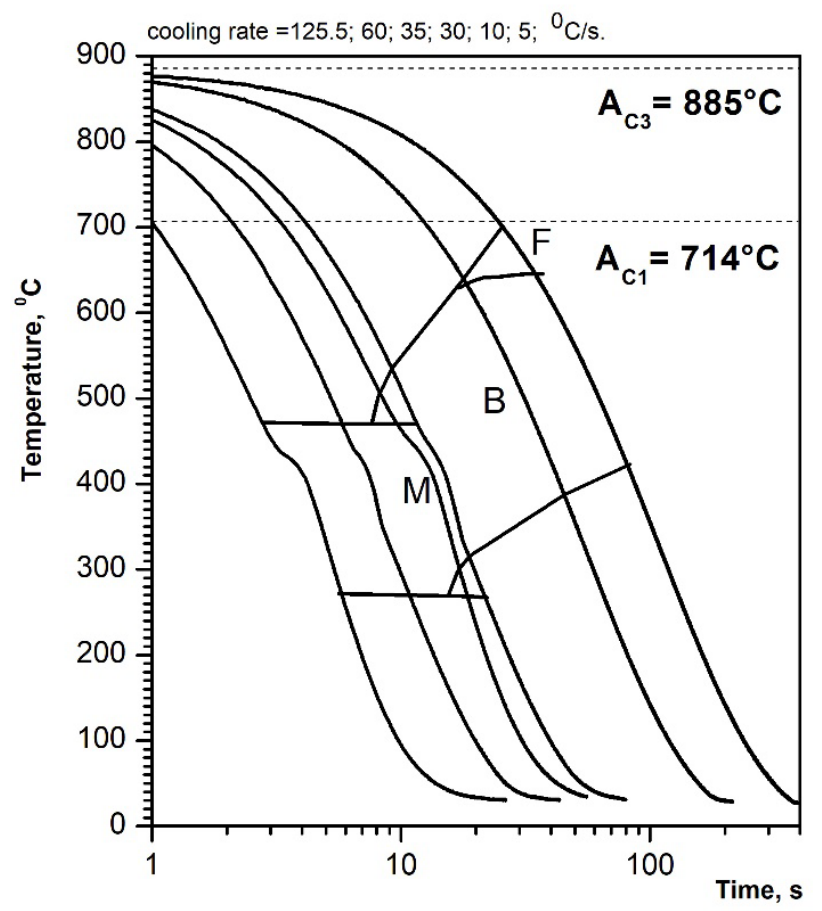

a)

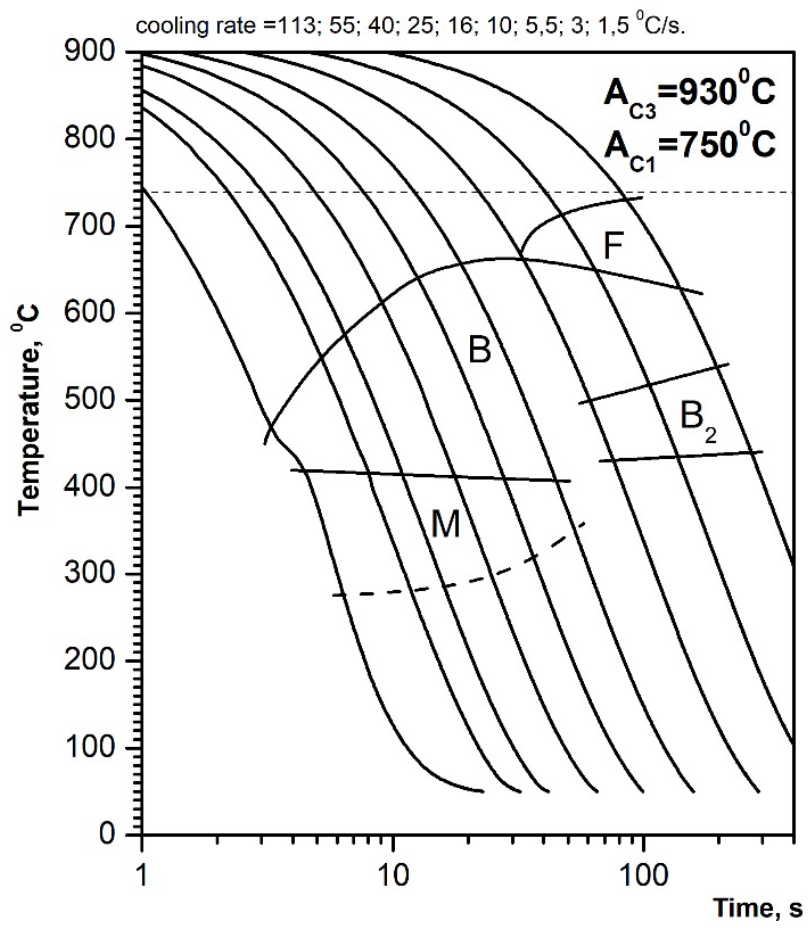

b)

Fig.8 CCT diagrams for investigated steels. a - TMCP steel grade S460M, b Normalized steel grade S355J2. 
Calculations of critical points (Eq. 3) using the Park equations [33,34] have close (within a $3 \%$ error) values: $A_{c 1}=716^{\circ} \mathrm{C}, A_{c 3}=878^{\circ} \mathrm{C}$ for $S 460 \mathrm{M} ; A_{c 1}=732^{\circ} \mathrm{C}, A_{c 3}=911^{\circ} \mathrm{C}$ for S355J2.

$$
\begin{aligned}
& \mathrm{A}_{c 1}\left({ }^{\circ} \mathrm{C}\right)=739-22.8 \mathrm{C}-6.8 \mathrm{Mn}+18.2 \mathrm{Si}+11.7 \mathrm{Cr}-15 \mathrm{Ni}-6.4 \mathrm{Mo}-5 \mathrm{~V}-28 \mathrm{Cu} \\
& \mathrm{A}_{c 3}\left({ }^{\circ} \mathrm{C}\right)=955-350 \mathrm{C}-25 \mathrm{Mn}+51 \mathrm{Si}+106 \mathrm{Nb}+100 \mathrm{Ti}+68 \mathrm{Al}-11 \mathrm{Cr}-33 \mathrm{Ni}-16 \mathrm{Cu}+67 \mathrm{Mo}
\end{aligned}
$$

An analysis of the equations shows that the differences in the critical points of these steels are due to differences in the micro-alloying elements. They differ in the content of such elements as V, S, Ti, and Nb. Unlike in S460M steel, the vanadium content is six times higher, while the sulfur is halved in $\$ 355 \mathrm{~J} 2$ steel. Considering the heating temperatures used in post-weld treatments, it is possible to estimate the amount of overheating for the investigated steels (Figure 9). Thus, for $S 460 \mathrm{M}$ steel $\Delta T_{A c 1}=36^{\circ} \mathrm{C}$ and $\Delta T_{A c 3}=67^{\circ} \mathrm{C}$, whereas for S355J2 steel $\Delta T_{A c 1}=0^{\circ} \mathrm{C}$ and $\Delta T_{A c 3}=20^{\circ} \mathrm{C}$. This suggests that the transformation of austenite in S460M steel will proceed more intensively. The transition from $\alpha$-Fe to $\gamma$-Fe (austenite) begins when the critical point $A_{c 1}$ is reached and completely ends at $A_{c 3}$. The completion of the phase transformation process is characterized by the formation of austenite and the disappearance of pearlite. This newly formed austenite, however, will be heterogeneous even in the volume of the selected grain. To obtain homogeneous austenite during heating, it is necessary not only to cross the $A_{c 3}$ point but to overheat the steel above this point, or dwell at whatever the current temperature is. Such steps allow completing the diffusion processes inside the austenite grain. The rate of transformation largely depends on the initial structure of the steel, the dispersity of cementite, and its shape. The smaller the cementite particles and the larger their total surface, the faster this transformation occurs. Consequently, the selected treatment temperatures for S460M steel will have a destructive effect on the structure and, therefore, on the mechanical properties. Due to the slight overheating of S355J2 steel, this factor does not significantly affect strength. At these conditions, the grain size is increased, as shown above in 1.5 times for S355J2 steel (overheating is equal to $20^{\circ} \mathrm{C}$ at Ac3 point), while for S460M steel (overheating is equal to $67^{\circ} \mathrm{C}$ at $\mathrm{Ac} 3$ point) in 3.5 times. According to the Hall-Petch relation Eq. (2) the strength for the S460M steel is decreased by $\sim 125 \mathrm{MPa}$, which is in good agreement with the observed experimental data (Fig. 1a). 


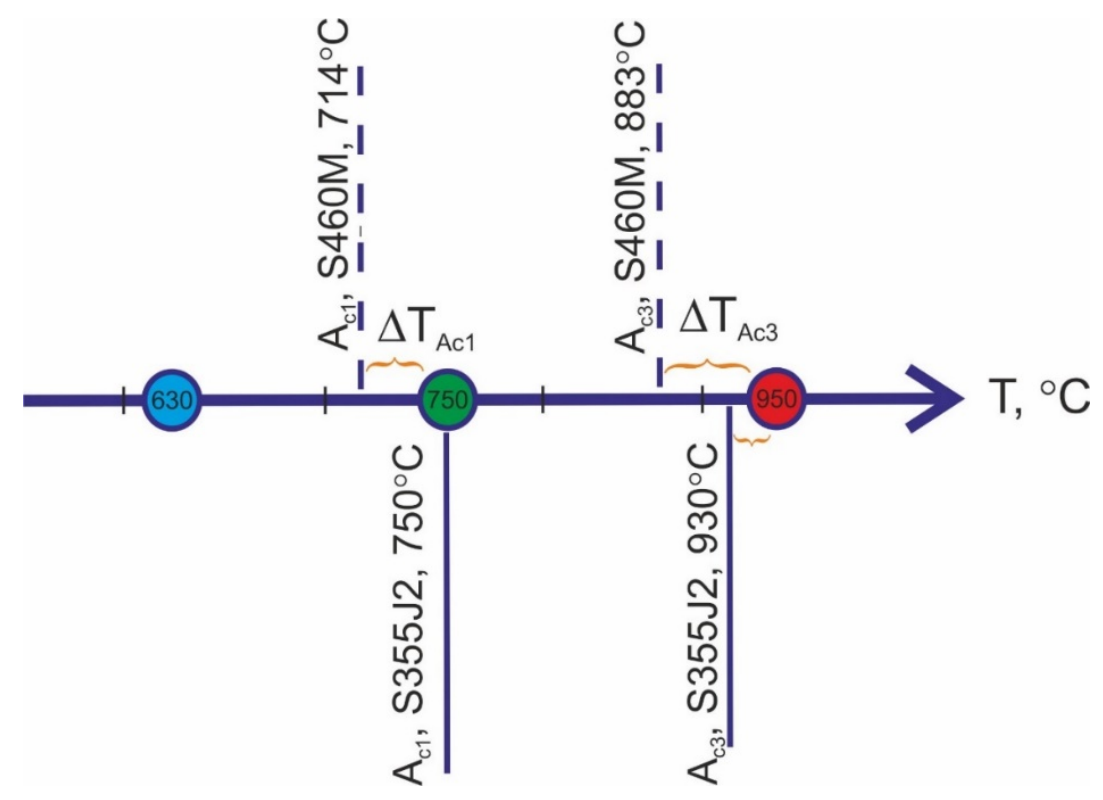

Fig. 9. Infographic of high-temperature heating of the investigated steels.

\subsection{Accumulated strain}

In addition to the heating temperature for treatment and the exposure time, the final grain size also depends on the initial metal structure after plastic deformation. After the various types of metal processing by plastic deformation (e.g., rolling, forging, and drawing $[35,36])$ in steel, the stability of austenite above the critical temperature changes. The dynamics of relaxation and recrystallization processes also varied. The metals subjected to plastic deformation are less thermally stable [37] because they contain more defects in their crystal structure, and hence lower temperatures are necessary to activate their movement. An increase in the accumulated strain leads to an increase in the dislocation density, mainly in the zones adjacent to the grain boundaries. In other words, the energy stored in grain boundaries, becomes the additional driving force for grain growth, i.e. the smaller grains the higher the driving force. At a critical accumulated strain, the grain grows very quickly due to the mechanism of grain growth. The dislocation structure of the grain boundaries, in this case, is such that, upon heating, several grains merge into one large grain. Dislocations of a different sign annihilate, and the boundary between the individual grains is cleared and gradually disappears. When the strain exceeds the critical level, the active grain growth mechanism is replaced by a primary recrystallization mechanism (occurrence of the new grains nuclei and their growth). Figure 10 presents the LAM maps for the investigated steels. 


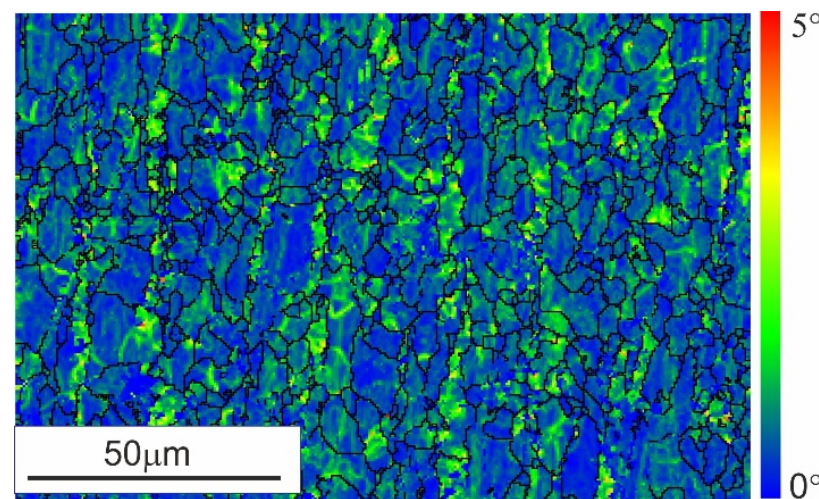

a)

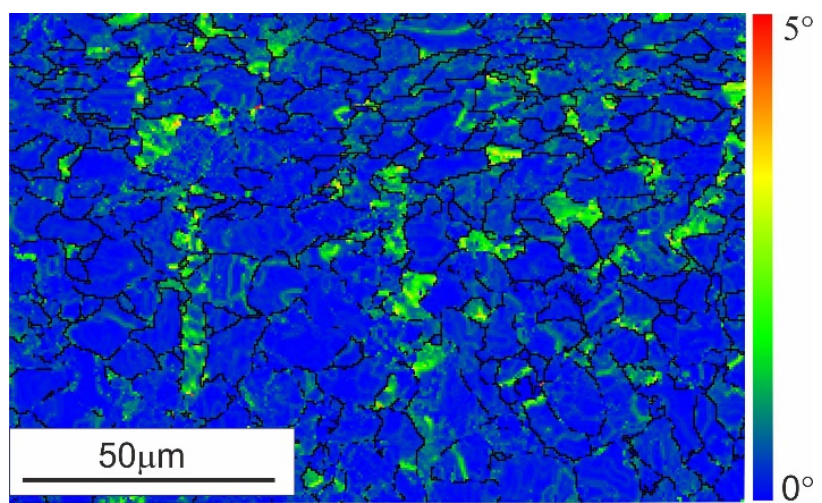

b)

Fig. 10. The LAM maps for the as-rolled steels (initial state), constructed according to the EBSD data. a - steel grade S460M (TMCP); b - steel grade S355J2 (normalized);

From the above results, it is clearly seen that the areas with high dislocation density in S460M steel are noticeably larger than that in S355J2 steel. As above noted, this is one of the factors influencing the intensive grain growth in S460M steel during further hightemperature $\left(950^{\circ} \mathrm{C}\right)$ heating.

\subsection{Steel deoxidizing}

There are two types of steel microstructure: hereditarily fine-grained and coarsegrained. The first is characterized by a low tendency for grain growth, while the second has increased growth. The bigger grain of austenite, the bigger the ferrite grain after austenite decomposition [27]. Austenitic grains grow only when heated; hence, the maximum heating temperature of the steel and its hereditary origin determines the final grain size. More notably, even different melts of the same steel grade may have a different ability for grain growth. The steel deoxidation method matters here. Steel deoxidized only with ferromanganese or ferrosilicon is hereditarily coarse-grained, and steel additionally deoxidized with aluminum is fine-grained $[27,30]$. The aluminum introduced into the liquid steel before crystallization forms the nitride compound AIN with the nitrogen dissolved in the liquid steel. This compound is dissolved in the liquid steel, and after its crystallization and subsequent cooling, it is released in the form of submicrocrystalline particles (so-called "nonmetallic dust"), which are located along the grain boundaries, preventing them from growing.

As shown in Figure 7, the average grain size of the HAZ metal of both steels after high-temperature heating is close enough, which is explained by the peculiarities of the microstructure of the HAZ metal before heating. First of all, the metal in the HAZ has no strain hardening as well as the texture of rolling. The HAZ of both steels has a mixture of bainite/ferrite structure, so to restore the grain size of the parent austenite, a reconstruction (a first approximation) was carried out using the ARPGE software (Figure 11). 


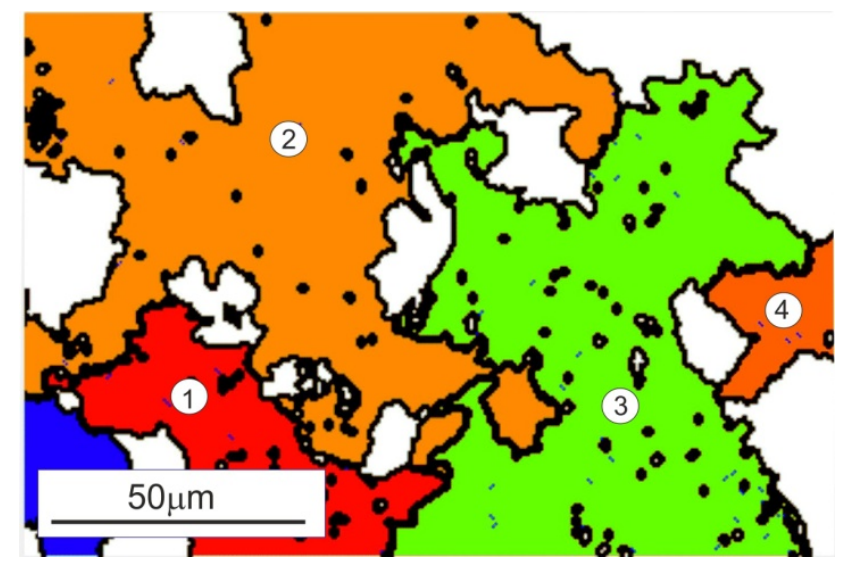

a)

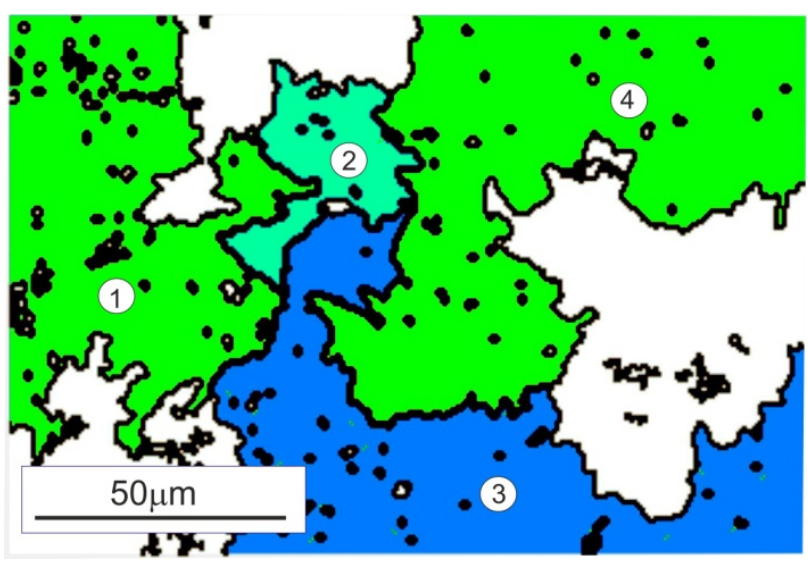

b)

Fig. 11. Parent austenite grains of the investigated steels HAZ metal, obtained by means of ARPGE software (The grains are described by different colors). a - steel grade S460M; b - steel grade S355J2

This reconstructed microstructure represents an estimation of parent austenite grains for the HAZ metal. The reconstructed grains of parent austenite are numbered and presented in different colors; black dots in the bulk of the grains and white regions correspond to unsolved points. It can be seen that parent austenitic grains for both the investigated steels have a close size distribution due to the influence of the welding thermal cycle (rapid heating, short exposure time, and rapid cooling). In this case, the exposure time of the metal above the phase recrystallization temperature $\left(A_{c 3}\right)$ is not enough for complete diffusion processes. Differences in the microstructure are significantly noticeable though when heating the steel in its initial state at high temperature. (Figure 6). Abnormal grain growth of 3.5 times compared with the initial state for S460M steel may indicate its hereditary coarse grain. It is also important to note that the aluminum content in it is almost half that of S355J2 steel.

\subsection{Carbonitrides}

The carbide-forming elements have a significant effect on the microstructure and mechanical characteristics of the steel, which is caused by the slowing down of diffusion processes. The mechanism of carbide action for II- group (interstitial phase, MeC) is that they are hardly soluble in austenite even at high temperatures, while carbides of the I -group ( $\mathrm{Me}_{3} \mathrm{C}, \mathrm{Me}_{23} \mathrm{C}_{6}, \mathrm{Fe}_{3} \mathrm{C}, \mathrm{Cr}_{23} \mathrm{C}_{6}$ ) dissolve easily [27,38]. The order of carbide dissolution is determined by their stability and the degree of transition into the solution, i.e., the carbide amounts. Non-carbide-forming elements ( $\mathrm{Si}, \mathrm{Ni}, \mathrm{Co}$ ) prevent the dissolution of carbides in austenite. $\mathrm{Mn}$ and $\mathrm{Cr}$ (the carbides of which dissolve in austenite at lower temperatures), when dissolved in austenite, will increase the solubility of the VC [27]. Titanium will not have such an effect since its carbide (in low-carbon steel $\mathrm{C}<0.1 \mathrm{wt} \%$ ) will transfer to austenite 
at a higher temperature. In the case of a treatment temperature of $950{ }^{\circ} \mathrm{C}, \sim 0.1 \% \mathrm{~V}, \sim 0.01 \%$ $\mathrm{Nb}, \sim 0.008 \% \mathrm{Ti}$ dissolve in austenite [27] and the excessive content of these elements will form a hardening carbide phase which has a barrier effect on the migrating grain boundary. The dissolution or coagulation of dispersed phases in austenite eliminates the barrier effect of the particles (Zener pinning effect). The maximum grain size of austenite $d$ depends on the size of the particles and their quantity (Eq. Zener) [39]:

$$
d=\frac{4}{3} \cdot \frac{r}{f}
$$

where $r$ is the radius of the particles, and $f$ is their volumetric fraction. Assuming that the volume fraction of the hardening particles is $1 \%$, then in the case of their size of $100 \mathrm{~nm}, d$ $=7 \mu \mathrm{m}$; and with an increase to $500 \mathrm{~nm}, d=35 \mu \mathrm{m}$. Consequently, the larger the volume fraction of undissolved particles retained in the steel upon heating and the smaller their size, the more fine-grained austenite is obtained.
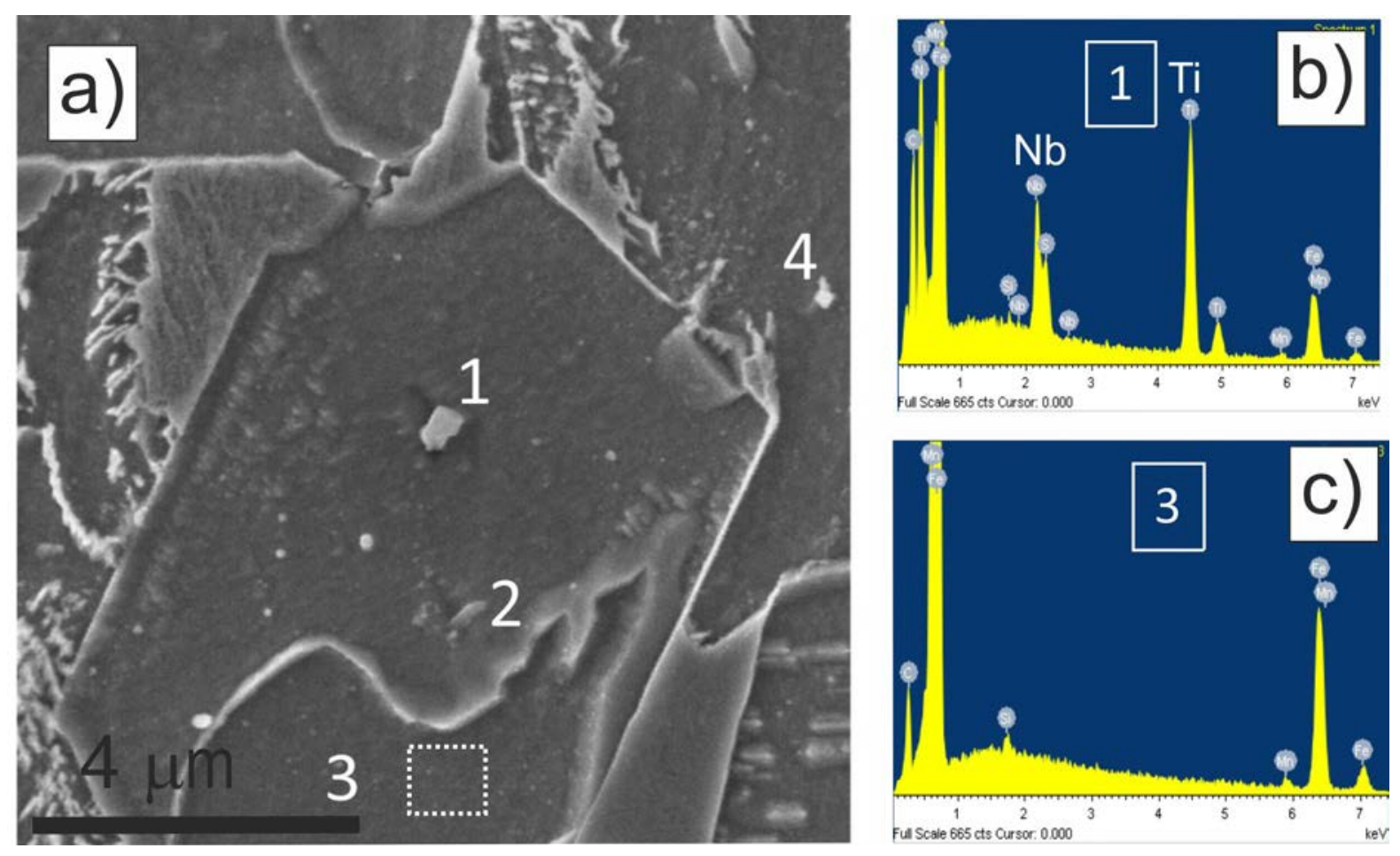

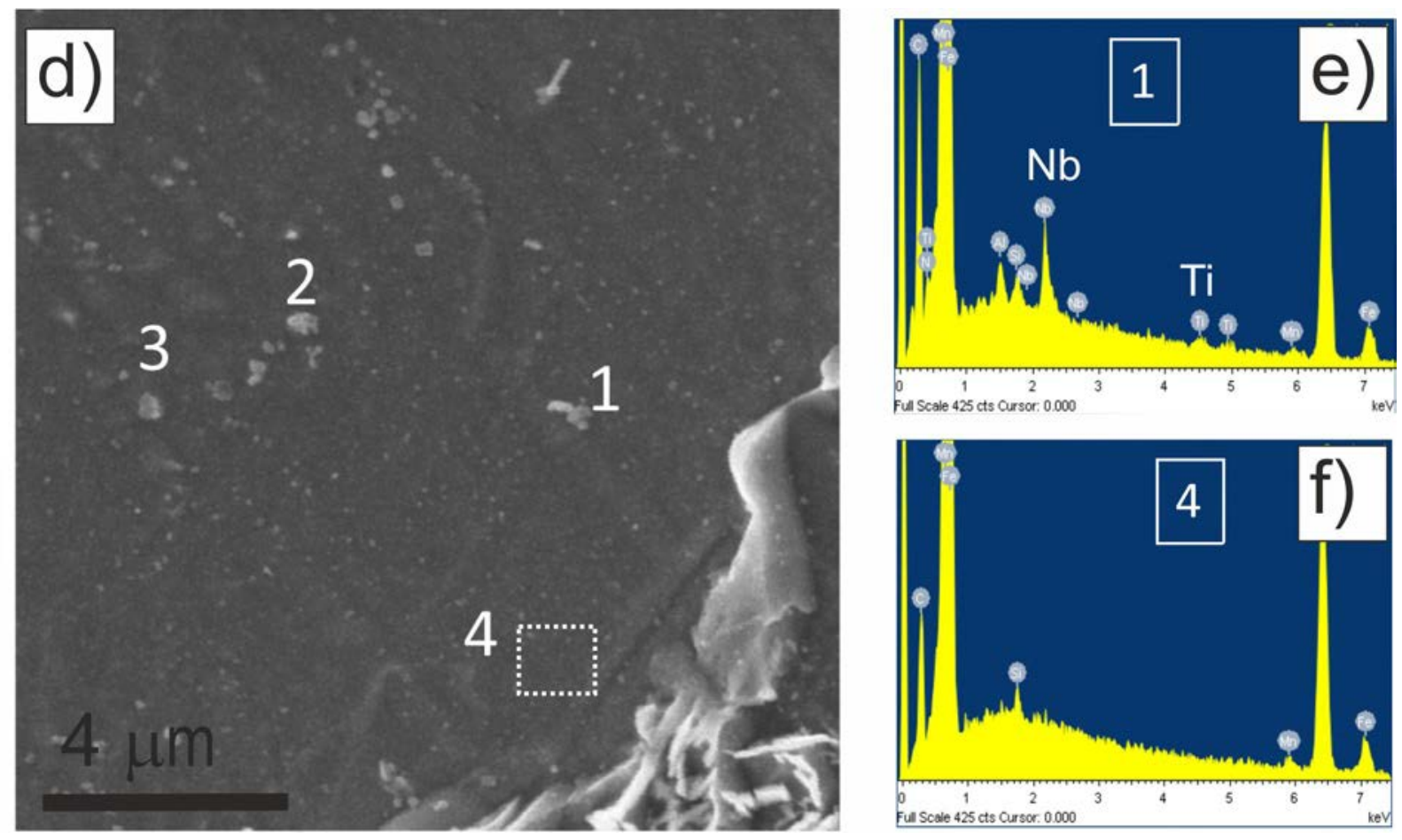

Fig. 12. The SEM microstructure ( $a$ and $d)$ and selected areas EDS Spectra (b, c, e, and f) of the as-rolled steels after high-temperature heating to $950{ }^{\circ} \mathrm{C}$. a, b, and c-steel grade S460M; $d, e$, and $f$ - steel grade S355J2. EDS spectra numbers correspond to numbers on the SEM micrographs.

The microstructures in Figure 12 illustrate the morphology of hardening particle distribution (marked with numbers 1-4) for the investigated steels after heating to $950{ }^{\circ} \mathrm{C}$. It can be seen after heating to this temperature that S355J2 steel has more dispersed inclusions with a size of $\sim 100 \mathrm{~nm}$, while their number in S460M steel is less and can be found rather large. The results of the EDS analysis carried out at the marked points (Figure 12, Table 3) confirm that the selected particles in S355J2 steel are carbonitrides of Ti and $\mathrm{Nb}$.

Table 3. Chemical composition of the selected points for the investigated steels

\begin{tabular}{|l|c|l|l|l|l|l|l|l|l|l|}
\hline Spectrum & N & Al & Si & S & Ti & V & Mn & Fe & Nb & Total \\
\hline \multicolumn{10}{|c|}{ TMCP S460M steel } \\
\hline Spectrum 1 & 10.84 & 0.13 & 0.26 & 1.36 & 30.09 & - & 2.40 & 44.29 & 10.63 & 100.00 \\
\hline Spectrum 2 & - & 0.00 & 0.43 & - & - & - & 1.89 & 97.68 & - & 100.00 \\
\hline Spectrum 3 & - & 0.00 & 0.34 & - & - & - & 2.60 & 97.06 & - & 100.00 \\
\hline Spectrum 4 & - & 0.00 & 0.42 & - & 2.22 & 1.07 & - & 91.42 & 4.86 & 100.00 \\
\hline \multicolumn{10}{|c|}{ Normalized S355J2 steel } \\
\hline Spectrum 1 & 1.67 & 0.49 & 0.31 & - & 0.46 & - & 1.29 & 92.16 & 3.62 & 100.00 \\
\hline Spectrum 2 & 2.72 & 2.14 & 0.30 & - & 0.52 & - & 1.72 & 92.21 & 0.39 & 100.00 \\
\hline Spectrum 3 & 0.89 & 0.42 & 0.29 & - & 0.37 & - & 1.24 & 96.40 & 0.38 & 100.00 \\
\hline Spectrum 4 & - & 0.00 & 0.33 & - & - & - & 2.08 & 97.59 & - & 100.00 \\
\hline
\end{tabular}


In addition, the presence of AIN particles was also detected. This indicates that the highstrength state of S355J2 steel is achieved due to the formation of a hardening carbide phase, which inhibits grain growth at high heat treatment temperatures ( $\left.T \geq A_{c 3}\right)$.

For the S460M steel, it was revealed that one inclusion is niobium and titanium carbonitride, while its dimensions ( $-500 \mathrm{~nm})$ are significantly larger than those observed in the S355J2 steel. Considering that the volume fraction of hardening particles is small, it can be concluded that when heated above $A_{c 3}$, they could go into solid solution, followed by segregation in the form of large carbides. This is an additional factor that induces intense grain growth in the TMCP (S460M) steel during heating. In such particular conditions, the pinning effect is suppressed that causes increasing the grain size of S460M steel up to 3.5 times (from 10 to $35 \mu \mathrm{m}$ ). Also, as the dimensions of the hardening precipitations increase, the coherence of the interfaces with the matrix is lost, leading to a drop in the mechanical characteristics [40].

\section{Conclusions}

The effect of the high-temperature heat treatment on the mechanical properties and microstructure of the HSLA steels processed by various technologies have been investigated. It has been shown that at a temperature $\mathrm{T} \leq 650{ }^{\circ} \mathrm{C}$, associated with the treatment of relieving welding stresses, the mechanical properties of the investigated steels are stable within the error limits. At a temperature $\mathrm{T} \leq 750^{\circ} \mathrm{C}$ (for example, enough for thermal shaping) in the steel, obtained by TMCP, the yield strength decreases from $15 \%$ to more than $25 \%$ at $\mathrm{T} \leq 950^{\circ} \mathrm{C}$ (for example, hot stamping). The mechanical properties of the normalized steel are stable at all studied temperatures. It has been established that the decrease in the mechanical properties of the TMCP steel is due to intensive grains growth at $\mathrm{T}>\mathrm{A}_{\mathrm{c} 3}$ conditioned by several factors, e.g., high dislocation density, rolling texture, dissolution, and uncontrolled growth of the hardening precipitation (carbonitrides). The stability of the properties for normalized steel at T > Ac3 is caused by the high stability of austenite due to the effect of preventing the intensive growth of the grains (Zener pinning).

The regularities of the changes in the mechanical properties of the HAZ metal (rapid heating/cooling) in both steels under heating to $950{ }^{\circ} \mathrm{C}$ are similar. It results from the similar sizes of the parent austenite grains in the HAZ metal. Such particular effects for the TMCP steel HAZ metal are due to the absence of factors such as deformation hardening and rolling texture. They are eliminated by heating by the thermal cycle of welding. 
Thus, the factors associated with mechanical treatment procedure (deformation hardening, rolling texture) as well as microalloying (precipitation hardening) play key roles in structure stability under the following high-temperature heat treatment.

From the practical point of view, the HSLA steel obtained by TMCP can be used in the manufacturing of welded steel structures that do not require hot straightening and stamping operations. Heating is allowed not higher than $A_{c 1}\left(714^{\circ} \mathrm{C}\right)$ for welding stress relieving. The HSLA steel, obtained through normalizing, may be used in the manufacture of welded steel structures involving consequent treatment at temperatures of up to $950{ }^{\circ} \mathrm{C}$.

\section{Novelty:}

- The decrease in the mechanical properties of TMCP steel at $T>A_{c 3}$ is due to intensive grain growth

- The high dislocation density, texture, dissolution of precipitates induces intensive grain growth under following high-temperature heating

- The stability of the properties of normalized steel at T > $A_{c 3}$ provided by high stability of the austenite

- Zener pinning effect plays a key role in preventing the intensive growth of the grains at $\mathrm{T}>\mathrm{A}_{\mathrm{c} 3}$

\section{Contributor Roles Taxonomy}

Anatoliy Zavdoveev, Thierry Baudin, Hyoung Seop Kim, Massimo Rogante and Mykola Skoryk Conceptualization, Methodology Anatoliy Zavdoveev, Hyoung Seop Kim, Valeriy Poznyakov Supervision Anatoliy Zavdoveev, Thierry Baudin, Yuriy Demchenko, Victor Zhukov and Mark Heaton Data curation, Writing- Original draft preparation. All authors discussed the results and commented on the manuscript.

\section{Acknowledgments}

The research work reported in this paper was funded by the National Academy of Sciences of Ukraine [grant number 0117U001666]. The authors are grateful to Dr. C. Cayron for kindly providing ARPGE program and Dr. B. Beausir for kindly providing ATEX software, Prof. D. Raabe, Dr. S.Mironov, Dr. A. Kulakowska for many fruitful discussions, Dr. S. Moskalyuk, Dr. A. Maksimenko, Dr. S. Jdanov, Dr. V.Kostin for help in experiments. 
Conflict of interest: Anatoliy Zavdoveev, Valeriy Poznyakov, Thierry Baudin, Massimo Rogante, Hyoung Seop Kim, Mark Heaton, Yuriy Demchenko, Victor Zhukov and Mykola Skoryk declare that they have no conflict of interest.

Data availability: The raw/processed data required to reproduce these findings cannot be shared at this time due to technical or time limitations.

\section{References}

[1] B. De Meester, The weldability of modern structural TMCP steels, ISIJ Int. 37 (1997) 537-551. https://doi.org/10.2355/isijinternational.37.537.

[2] E. Ufuah, J. Ikhayere, Elevated Temperature Mechanical Properties of Butt-Welded Connections Made with High Strength Steel Grades S355 and S460M BT - Design, Fabrication and Economy of Metal Structures, in: Des. Fabr. Econ. Met. Struct., 2013.

[3] C.H. Lee, H.S. Shin, K.T. Park, Evaluation of high strength TMCP steel weld for use in cold regions, J. Constr. Steel Res. (2012).

https://doi.org/10.1016/j.jcsr.2012.02.012.

[4] S.F. Medina, M. Gómez, P.P. Gómez, Effects of v and Nb on static recrystallisation of austenite and precipitate size in microalloyed steels, J. Mater. Sci. (2010). https://doi.org/10.1007/s10853-010-4616-z.

[5] C. Fossaert, G. Rees, T. Maurickx, H.K.D.H. Bhadeshia, The effect of niobium on the hardenability of microalloyed austenite, Metall. Mater. Trans. A. (1995). https://doi.org/10.1007/BF02669791.

[6] A. V. Nazarov, E. V. Yakushev, I.P. Shabalov, Y.D. Morozov, T.S. Kireeva, Comparison of weldability of high-strength pipe steels microalloyed with niobium, niobium and vanadium, Metallurgist. (2014). https://doi.org/10.1007/s11015-0149821-6.

[7] G.M. Reddy, T. Mohandas, D.S. Sarma, Cold cracking studies on low alloy steel weldments: effect of filler metal composition, Sci. Technol. Weld. Join. (2003). https://doi.org/10.1179/136217103225005552.

[8] R. Demarque, E.P. dos Santos, R.S. Silva, J.A. de Castro, Evaluation of the effect of 
the thermal cycle on the characteristics of welded joints through the variation of the heat input of the austhenitic AISI 316L steels by the GMAW process, Sci. Technol. Mater. 30 (2018) 51-59. https://doi.org/https://doi.org/10.1016/j.stmat.2018.09.001.

[9] S. Lee, B.C. Kim, D. Kwon, Correlation of microstructure and fracture properties in weld heat- affected zones of thermomechanically controlled processed steels, Metall. Trans. A. (1992). https://doi.org/10.1007/BF02651759.

[10] M. Natschläger, R. Egger, S.A. Kapl, Thermomechanically Rolled Heavy Plates for PenstocksThermomechanisch gewalzte Grobbleche für Druckrohrleitungen, WASSERWIRTSCHAFT. (2018). https://doi.org/10.1007/s35147-015-0528-9.

[11] J. Brozda, M. Zeman, M. Lomozik, The weldability of thermomechanically rolled S460ML steel, Weld. Int. (2000). https://doi.org/10.1080/09507110009549236.

[12] E. Pashinska, V. Varyukhin, A. Zavdoveev, V. Stolyarov, Effect of rolling with shear technology on structure, properties and plasticity of low-carbon steel, in: Spec. Ed. 10th Int. Conf. Technol. Plast. ICTP 2011, 2011.

[13] K. Krasnowski, Effect of heat treatment of S420MC steel joints on their mechanical properties and fatigue strength, Biul. Inst. Spaw. (2013) 23-31.

[14] J. Górka, Weldability of Thermomechanically Treated Steels Having a High Yield Point, Arch. Metall. Mater. (2015). https://doi.org/10.1515/amm-2015-0076.

[15] A. Mehditabar, G.H. Rahimi, M. Krol, S.E. Vahdat, Effect of Heat Treatment on the Properties of AlCu26Si8, in: Int. J. Cast Met. Res., 2019: pp. 278-288. https://doi.org/10.1080/13640461.2019.1692457.

[16] J. Górka, Assessment of Steel Subjected to the Thermomechanical Control Process with Respect to Weldability, Metals (Basel). (2018). https://doi.org/10.3390/met8030169.

[17] A. Zavdoveev, V. Pozniakov, M. Rogante, S. Jdanov, A. Maksimenko, Weldability of S460M high strength low-alloyed steel, in: Mech. Technol. Struct. Mater., 2017.

[18] A. Zavdoveev, T. Baudin, E. Pashinska, M. Skoryk, Preparation of metallographic specimens for electron backscatter diffraction, Emerg. Mater. Res. 6 (2017) 260264. https://doi.org/10.1680/jemmr.16.00117.

[19] G.F. Vander Voort, Metallographic Specimen Preparation for Electron Backscattered 
Diffraction Part I, Pract. Metallogr. (2013). https://doi.org/10.3139/147.110151.

[20] A. Karmakar, M. Mandal, A. Mandal, M. Basiruddin Sk, S. Mukherjee, D. Chakrabarti, Effect of Starting Microstructure on the Grain Refinement in Cold-Rolled Low-Carbon Steel During Annealing at Two Different Heating Rates, Metall. Mater. Trans. A Phys. Metall. Mater. Sci. (2016). https://doi.org/10.1007/s11661-015-3248y.

[21] Q. Ma, X. Zhao, D. Meng, C. Dong, Z. Hou, R.D.K. Misra, Microstructure and Hardness Evolution during Deformation near Ae3 in a Cr-Mn-Ti Gear Steel, Steel Res. Int. (2019). https://doi.org/10.1002/srin.201800332.

[22] B. Beausir, C. Fressengeas, Disclination densities from EBSD orientation mapping, Int. J. Solids Struct. (2013). https://doi.org/10.1016/j.jjsolstr.2012.09.016.

[23] C. Cayron, ARPGE : a computer program to automatically reconstruct the parent grains from electron backscatter diffraction data, J. Appl. Crystallogr. (2007). https://doi.org/10.1107/s0021889807048777.

[24] G. Larzabal, N. Isasti, J. Rodriguez-Ibabe, P. Uranga, Effect of Microstructure on Post-Rolling Induction Treatment in a Low C Ti-Mo Microalloyed Steel, Metals (Basel). (2018). https://doi.org/10.3390/met8090694.

[25] O. Berdnikova, V. Sydorets, T. Alekseienko, Structure and Properties of LaserWelded Joints from High-Strength Steels, Appl. Mech. Mater. (2014). https://doi.org/10.4028/www.scientific.net/amm.682.240.

[26] U. Mayo, N. Isasti, J.M. Rodriguez-Ibabe, P. Uranga, On the characterization procedure to quantify the contribution of microstructure on mechanical properties in intercritically deformed low carbon HSLA steels, Mater. Sci. Eng. A. 792 (2020) 139800. https://doi.org/https://doi.org/10.1016/j.msea.2020.139800.

[27] M.I. Gol'dshtein, S. V Grachev, Y.G. Veksler, Special steels, Moscow Metall. (1985) 408.

[28] M. Shome, O.P. Gupta, O.N. Mohanty, Effect of simulated thermal cycles on the microstructure of the heat-affected zone in HSLA-80 and HSLA-100 steel plates, Metall. Mater. Trans. A. 35 (2004) 985-996.

[29] K. Han, C.J. Van Tyne, B.S. Levy, Effect of strain and strain rate on the Bauschinger effect response of three different steels, Metall. Mater. Trans. A. 36 (2005) 2379_ 
2384.

[30] T.V.S. Rajan, C.P. Sharma, A. Sharma, Heat treatment: principles and techniques, PHI Learning Pvt. Ltd., 2011.

[31] J. Moon, C. Lee, Pinning efficiency of austenite grain boundary by a cubic shaped TiN particle in hot rolled HSLA steel, Mater. Charact. 73 (2012) 31-36.

[32] V.A. Kostin, G.M. Grigorenko, V.D. Poznyakov, T.O. Zuber, Structural Transformations of the Metal of Heat-Affected Zone of Welded Joints of HighStrength Armor Steels, Mater. Sci. 55 (2020). https://doi.org/10.1007/s11003-02000380-7.

[33] M. ALIBEYKI, H. MIRZADEH, M. NAJAFI, The effects of primary thermo-mechanical processing routes and intercritical annealing on the mechanical properties of st37 low carbon steel, Met. Mater. (2018). https://doi.org/10.4149/km_2018_5_297.

[34] A.A. Gorni, Steel forming and heat treating handbook, São Vicente, Brazil. 24 (2011).

[35] E. Pashinskaya, A. Zavdoveev, S. Mironov, V. Varyukhin, A. Maksakova, Effect of drawing with shear on structure and properties of low-carbon steel, Int. J. Mater. Res. 107 (2016) 239-244. https://doi.org/10.3139/146.111338.

[36] E. Pashinska, V. Varyukhin, M. Myshlaev, A. V. Zavdoveev, Formation of structure and properties of low-carbon steel under rolling with shear and cold drawing, Adv. Eng. Mater. (2014). https://doi.org/10.1002/adem.201300197.

[37] R. Song, D. Ponge, D. Raabe, Mechanical properties of an ultrafine grained C-Mn steel processed by warm deformation and annealing, Acta Mater. 53 (2005) 48814892. https://doi.org/10.1016/J.ACTAMAT.2005.07.009.

[38] H. Adrian, Thermodynamic model for precipitation of carbonitrides in high strength low alloy steels containing up to three microalloying elements with or without additions of aluminium, Mater. Sci. Technol. 8 (1992) 406-420. https://doi.org/10.1179/mst.1992.8.5.406.

[39] Y. Sun, R.J. Hebert, M. Aindow, Effect of heat treatments on microstructural evolution of additively manufactured and wrought $17-4 \mathrm{PH}$ stainless steel, Mater. Des. (2018). https://doi.org/10.1016/j.matdes.2018.07.015. 
[40] P. Tao, H. Yu, Y. Fan, Y. Fu, Effects of cooling method after intercritical heat treatment on microstructural characteristics and mechanical properties of as-cast high-strength low-alloy steel, Mater. Des. 54 (2014) 914-923. 